\title{
Pain-relief learning in flies, rats, and man: basic research and applied perspectives
}

\author{
Bertram Gerber, ${ }^{1,2,3,8}$ Ayse Yarali, ${ }^{4}$ Sören Diegelmann, ${ }^{1}$ Carsten T. Wotjak, ${ }^{5}$ \\ Paul Pauli, ${ }^{6}$ and Markus Fendt ${ }^{2,7}$ \\ ${ }^{1}$ Leibniz Institut für Neurobiologie (LIN), Abteilung Genetik von Lernen und Gedächtnis, 39118 Magdeburg, Germany; ${ }^{2}$ Center for \\ Behavioral Brain Sciences (CBBS), 39016 Magdeburg, Germany; ${ }^{3}$ Otto von Guericke Universität Magdeburg, Institut für Biologie, \\ 39106 Magdeburg, Germany; ${ }^{4}$ Leibniz Institut für Neurobiologie (LIN), Forschergruppe Molekulare Systembiologie des Lernens, \\ 39118 Magdeburg, Germany; ${ }^{5}$ Max-Planck-Institut für Psychiatrie, Abteilung für Stressneurobiologie und Neurogenetik, \\ Arbeitsgruppe Neuronale Plastizität, 80804 München, Germany; ${ }^{6}$ Universität Würzburg, Institut für Psychologie, Lehrstuhl für \\ Biologische Psychologie, Klinische Psychologie und Psychotherapie, 97070 Würzburg, Germany; ${ }^{7}$ Otto von Guericke Universität \\ Magdeburg, Institut für Pharmakologie und Toxikologie, 39120 Magdeburg, Germany
}

Memories relating to a painful, negative event are adaptive and can be stored for a lifetime to support preemptive avoidance, escape, or attack behavior. However, under unfavorable circumstances such memories can become overwhelmingly powerful. They may trigger excessively negative psychological states and uncontrollable avoidance of locations, objects, or social interactions. It is therefore obvious that any process to counteract such effects will be of value. In this context, we stress from a basic-research perspective that painful, negative events are "Janus-faced" in the sense that there are actually two aspects about them that are worth remembering: What made them happen and what made them cease. We review published findings from fruit flies, rats, and man showing that both aspects, respectively related to the onset and the offset of the negative event, induce distinct and oppositely valenced memories: Stimuli experienced before an electric shock acquire negative valence as they signal upcoming punishment, whereas stimuli experienced after an electric shock acquire positive valence because of their association with the relieving cessation of pain. We discuss how memories for such punishment- and relief-learning are organized, how this organization fits into the threat-imminence model of defensive behavior, and what perspectives these considerations offer for applied psychology in the context of trauma, panic, and nonsuicidal self-injury.

The acknowledged "negative" mnemonic effects of adverse experiences mostly relate to what happens before the onset of an aversive, painful event. However, there is a less widely acknowledged type of memory that relates to what happens after the offset of or after escape from such a painful event, at the moment of "relief" (Fig. 1) (we use "relief" to refer specifically to the acute effects of punishment offset; an equally legitimate yet broader use of the word in, e.g., "fear relief," encompasses any process that eases fear [Riebe et al. 2012]). Indeed, in experimental settings, it turns out that stimuli experienced before and during a punishing episode are later avoided as they signal upcoming punishment, whereas stimuli experienced after a painful episode can subsequently prompt approach behavior, arguably (Box 1) because of their association with the relieving cessation of pain (Konorski 1948; Smith and Buchanan 1954; Wolpe and Lazarus 1966; Zanna et al. 1970; Solomon and Corbit 1974; Schull 1979; Solomon 1980; Wagner 1981; Walasek et al. 1995; Tanimoto et al. 2004; Yarali et al. 2008, 2009b; Andreatta et al. 2010, 2012; Yarali and Gerber 2010; Ilango et al. 2012; Navratilova et al. 2012; Diegelmann et al. 2013b); for a corresponding finding in the appetitive domain, see Hellstern et al. (1998) and Felsenberg et al. (2013). Such relief can both support the learning of the cues associated with the disappearance of the threat and reinforce those behaviors that helped to escape it. Obviously, the positive conditioned

\footnotetext{
${ }^{8}$ Corresponding author

E-mail bertram.gerber@lin-magdeburg.de

Article is online at http://www.learnmem.org/cgi/doi/10.1101/lm.032995.113.

Freely available online through the Learning \& Memory Open Access option.
}

valence of and ensuing learned approach behavior toward such cues would decrease the probability of encountering the threat again and/or keep exposure time to a minimum. We review the literature of what is known, and discuss what should be asked, about the mechanisms of such punishment- and relief-learning in the fruit fly Drosophila, as well as in rat and in man, as in these three species fairly concordant approaches have been taken. This is timely, because despite the rich literature on punishment-learning (e.g., for reviews regarding Drosophila, see: Dubnau and Tully 2001; Heisenberg 2003; Gerber et al. 2004; Davis 2005; Keene and Waddell 2007; Kahsai and Zars 2011; regarding Aplysia, see: Lechner and Byrne 1998; Baxter and Byrne 2006; Benjamin et al. 2008; regarding rodents, see: Davis et al. 1993; Fendt and Fanselow 1999; LeDoux 2000; Maren 2001; Christian and Thompson 2003; Fanselow and Poulos 2005; Pape and Pare 2010; regarding monkeys, see: Davis et al. 2008; regarding humans, see: Rosen and Schulkin 1998; Öhman and Mineka 2001; Delgado et al. 2006; Öhman 2008; Davis et al. 2009; Milad and Quirk 2012), little is known about the neurobiological mechanisms or the psychological corollaries of relief-learning. Such knowledge would be important also from an applied perspective: The more distinct the underlying processes of punishment- and relief-learning are, the more likely they contribute independently to pathology, and the easier it will be to selectively interfere with either of them. 


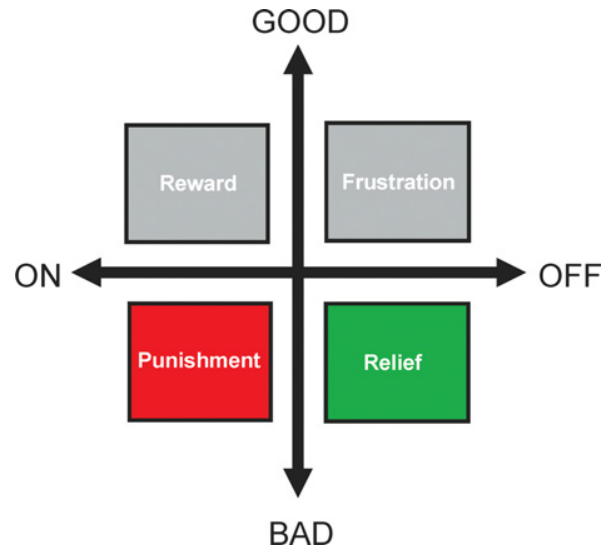

Figure 1. Event-timing and valence. For the "Good" and the "Bad" things in life, two aspects matter in particular: What made them happen? What made them cease? The diagram illustrates that the On-set of something good (top left; e.g., finding food, a salary increase) can act as a reward, while the On-set of something bad (bottom left; e.g., being stung by a bee, being sent to prison) can act as punishment. In turn, however, the Off-set of pain upon cooling the sting or release from prison entails an oppositely valenced aspect, relief (bottom right); likewise, having your lollipop pilfered as a kid or experiencing a salary cut entail negatively valenced frustration (top right). This review is chiefly concerned with the mnemonic consequences of punishment (red color code throughout) and relief (green color code throughout). We consistently plot those behavioral measures toward the top of the $y$-axes that indicate positive valence, and consistently plot measures indicating negative valence toward the bottom of the $y$-axes. Please note that despite detailed coverage of the good and the bad, the ugly is ignored throughout (Leone 1966).

\section{Fly}

\section{Punishment- and reward-learning}

When flies receive an odor followed by an electric shock, they subsequently avoid this odor because it predicts shock (Quinn et al. 1974; Tully and Quinn 1985). Specifically, a two-group reciprocaltraining paradigm is used (Fig. 3): One group of flies receives odor A followed by electric shock (denoted as "-"), whereas odor B is presented alone $(\mathrm{A}-/ \mathrm{B})$. The second group of flies receives reciprocal training $(\mathrm{A} / \mathrm{B}-)$. Then, both groups are tested in a forced-choice situation for their relative preferences between $\mathrm{A}$ and $\mathrm{B}$. It turns out that punishment of $\mathrm{A}$ tips the balance between $A$ and $B$ in favor of $B$, while punishment of $B$ biases choice in favor of A. An associative learning index (abbreviated as LI in Figs. 3, 5 [below]) is then calculated on the basis of this difference in preference between the two reciprocally trained groups. In addition to such punishment-learning, an appetitive version of the paradigm is available which uses sugar as reward (Tempel et al. 1983): When flies receive an odor together with a sugar reward, they subsequently show an increase in preference for this odor because it predicts reward. Thus, the paradigm is "bivalent" in the sense that it can reveal both decreases in odor preference after punishment-learning, and increases in odor preference after reward-learning. This bivalent nature of the task is essential for the ensuing discussion.

The cellular and molecular networks underlying short-term memory after punishment-learning have been studied in some detail (Fig. 4; regarding longer-term forms of memory and mechanisms of memory consolidation, see the recent studies by, e.g., Placais et al. 2012 or Perisse et al. 2013 and references therein). Briefly, upon presentation of an odor, a particular combination of olfactory sensory neurons on the antennae and maxillary palps is activated according to the ligand profiles of the respectively ex- pressed receptor proteins. As a rule, all sensory neurons expressing the same receptor protein then converge at a single glomerulus in the antennal lobe, where they provide output to mostly uniglomerular projection neurons. The combination of projection neurons activated by a given odor is shaped, in addition, by lateral connections among the antennal lobe glomeruli. In the next step, projection neurons connect to both mushroom body Kenyon cells and lateral horn neurons as the third-order processing stages (see Laurent et al. 2001 for a discussion of temporal-coding aspects in olfaction). The electric shock, in turn, triggers a reinforcement signal, likely in a subset of dopaminergic neurons which carry this signal to many if not all Kenyon cells (Schwaerzel et al. 2003; Riemensperger et al. 2005; Kim et al. 2007; Claridge-Chang et al. 2009; Mao and Davis 2009; Aso et al. 2010, 2012; Pech et al. 2013; for larval Drosophila, see Schroll et al. 2006; Selcho et al. 2009). In contrast, as mentioned above, only a subset of the Kenyon cells is activated by the odor. It is only in these particular Kenyon cells, due to the coincidence of the odor-induced activity and the shock-induced reinforcement signal, that an odor-shock short-term memory trace is formed. Such a memory trace conceivably consists in a modulation of connection between the Kenyon cells and their output neurons (Sejourne et al. 2011), with the AC-cAMP-PKA signaling cascade as one of the necessary processes involved in molecular coincidence detection (Zars et al. 2000; Thum et al. 2007; Blum et al. 2009; Tomchik and Davis 2009; for a similar conclusion for appetitive learning, see Gervasi et al. 2010; for discussions of purely physiology-based conclusions about memory trace localization, see Heisenberg and Gerber 2008; for a general critique of the concept of memory trace localization, see Menzel 2013). If, after training, the learned odor is perceived, activity in the mushroom body output neurons-by virtue of their modified input from the Kenyon cells-is altered such that conditioned olfactory avoidance can take place (Sejourne et al. 2011). Interestingly, in accord with prediction-error signaling (Rescorla 1988), punishment-trained odors not only enable conditioned behavior but also apparently induce feedback onto dopaminergic neurons (Riemensperger et al. 2005; see the seminal study of Hammer 1993 for a corresponding finding in honeybee appetitive learning). Other, nontrained odors support conditioned avoidance only to the extent that they are similar in quality (Niewalda et al. 2011; Campbell et al. 2013; Barth et al. 2014) and/or intensity (Yarali et al. 2009a) to the actually trained odor. Appetitive learning, using sugar as reward is, in principle, organized in a similar way (e.g., Schwaerzel et al. 2003; Keene et al. 2006; Trannoy et al. 2011), with at least two significant differences:

- It has been argued that, in addition to the Kenyon cells, there may be an odor-reward short-term memory trace in the projection neurons (Drosophila, Thum et al. 2007; honeybee, Menzel 2001; Giurfa and Sandoz 2012; Menzel 2012; but see Peele et al. 2006). However, in Drosophila at least, independent confirmation of this is so far lacking (see discussions in Heisenberg and Gerber 2008; Michels et al. 2011).

- The reinforcing effect of reward involves aminergic neurons distinct from those mediating punishment (Schwaerzel et al. 2003; Burke et al. 2012; Liu et al. 2012), such that distinct sets of Kenyon cell output synapses are likely to be modulated to accommodate conditioned approach.

The net effect of driving or blocking signaling through a set of dopaminergic neurons covered by the TH-Gal4 expression pattern is to induce or impair, respectively, aversive memories (e.g., Schwaerzel et al. 2003; Schroll et al. 2006; Aso et al. 2010, 2012). The corresponding manipulations using the TDC-Gal4 expression pattern to drive octopaminergic neurons, or the $t \beta H^{M 18}$ mutant (CG1543) to impair octopamine biosynthesis, have 
BOX 1. Relief-learning—safety-learning

We use the term relief-learning specifically to imply the learning of an association between a stimulus and the offset of punishment. It was Konorski (1948) who initially proposed that the occurrence of a stimulus during the falling phase of a punishment signal could result in a positively valenced memory for this stimulus. In other words, in addition to their punishing effect, punishments may induce a delayed state of relief supporting positively valenced memories.

An alternative view is that repeated exposure to the punishment within the experimental context establishes this context as a dangerous one. Within such a dangerous context, a stimulus that is presented in an explicitly unpaired manner with the punishment could come to signal a subsequent period of safety. In other words, the actual absence of a contextually predicted punishment during and after the stimulus can lead to a positive prediction error ("better-than expected"), supporting a positively valenced memory for it (Rescorla 1988 and references therein).

Safety-learning, but not relief-learning, would thus be possible with unpaired or temporally randomized presentations of stimulus and punishment (for review, see Kong et al. 2013). As in such safetylearning procedures, the stimulus becomes a conditioned inhibitor predicting the nonoccurrence of the punishment and can reduce contextual fear, increase the exploration of unprotected environments, act as a positive secondary reinforcer, reduce immobility in the forced swim test, ameliorate the consequences of chronic mild stress, and promote neurogenesis (Rogan et al. 2005; Pollak et al. 2008; Christianson et al. 2012). Notably, after safety-learning of an auditory stimulus, less-than baseline evoked auditory potentials are induced in the lateral amygdala but increased evoked potentials in the caudoputamen (Rogan et al. 2005). At the same time, there is an activation of inhibitory pathways inside the amygdala that is different from those activations underlying fear extinction (Amano et al. 2010). No amygdaloid effects are found for relief-learning, however (see main text) (Andreatta et al. 2012). We finally note that neurons in the basolateral amygdala that show increased firing to a safety-learned stimulus appear to partially overlap with those activated by reward-related stimuli (Sangha et al. 2013).

Returning to procedures that consistently present the stimulus shortly after punishment, the issue is that under these conditions theoretically relief- as well as safety-learning could occur (see Fig. 2). How can one, in these cases, experimentally discriminate between relief- and safety-based explanations (see also discussions in Wagner and Larew 1985; Malaka 1999)?

- In a repetitive training design, safety-learning should monotonically decrease as the inter-stimulus interval (ISI) lengthens, because the stimulus moves closer in time toward the next punishment, shortening the following safety period. In most preparations looked at, the ISI-dependency appears bell-shaped (Plotkin and Oakley 1975; Maier et al. 1976; Tanimoto et al. 2004; for related findings, see Hellstern et al. 1998; Franklin et al. 2013a; for a counter-example, see Moscovitch and LoLordo 1968), fitting more naturally to a relief-based explanation, as the relief signal peaks shortly after punishment offset. However, the differences in the shape of the ISI-functions as proposed by relief- and safety-based models are subtle (Malaka 1999 loc. cit. Figs. 4b,5) and difficult to ascertain experimentally, in particular when the learning scores are low.

- Safety-learning arguably requires multiple training trials, because only when the context is sufficiently "charged" by previous trials will there be a positive prediction error during the subsequent trials, and the stimulus can become a safety-signal. While a single presentation of a stimulus with punishment offset can result in a positively valenced memory (e.g., Wagner and Larew 1985; for related findings, see Hellstern et al. 1998; Franklin et al. 2013a), in most cases multiple pairings are required (Heth 1976 and references therein; for Drosophila, see Yarali et al. 2008). Note that, unless one assumes implausibly rapid context-learning, the sufficiency of a single training trial argues against a safety-based explanation. A requirement for multiple trials, on the other hand, is consistent with both relief- and safety-based explanations (for detailed discussions, see Heth 1976; Wagner and Larew 1985; Malaka 1999).

- As noted, safety-learning should rely on the value of the experimental context as a signal for the punishment. In rats, Chang et al. (2003) argued for such context-dependency and thus for a safetybased explanation: An extinction treatment for the context-punishment association diminished the effect of prior punishment-stimulus training. However, following a very similar reasoning, Yarali et al. (2008) tested in a Drosophila paradigm whether the initial punishment-stimulus pairings of a multiple-trial training session can be substituted by mere exposure to punishment within the experimental context. This was not found to be the case, offering no support for a safety-based explanation. Neither argument is particularly strong, though, because Chang et al. (2003) did not actually demonstrate extinction of the context-punishment association, and because in flies direct evidence for contextual learning under the employed conditions is lacking. We note that in honeybee learning using odors and a sugar reward, changing the context during the inter-stimulus interval leaves scores unaffected, also failing to provide evidence for context-mediation (Hellstern et al. 1998).

Obviously, these experimental strategies have given mixed or tentative results across studies, paradigms, and species, making firm and general conclusions premature. By our assessment, however, the relief-based explanation seems to be in the lead at this point-when it comes to grasping the mnemonic processes related to punishment offset.

We note that despite the above-sketched conceptual dichotomy, animals may well have the capacity for both relief- and safetylearning, so the parametric boundary conditions for their respective operation and their underlying mechanisms would need to be clarified. Indeed, one can imagine experiments that would parametrically turn experimental procedures ideal for relief-learning (pairing of the stimulus with punishment offset) into paradigms optimal for safetylearning (unpaired presentations of punishment and stimulus).

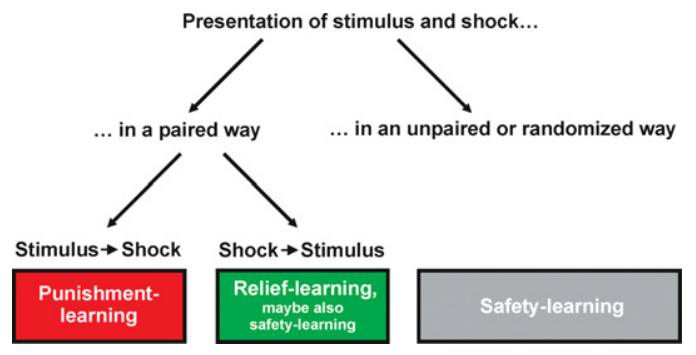

Figure 2 corresponding net effects in the appetitive domain (e.g. Schwaerzel et al. 2003; Schroll et al. 2006; Burke et al. 2012). There is, however, clearly no simple dichotomy in reinforcement processing, dopamine for punishment and octopamine for reward: A subset of dopaminergic neurons from the so-called
PAM-cluster mediates appetitive reinforcement (Burke et al 2012; Liu et al. 2012), and genetic distortions of the dopamine receptor gene Dop1R1 (CG9652, also known as dumb) fittingly compromise both appetitive and aversive learning (Kim et al. 2007; Burke et al. 2012; Qin et al. 2012). Current work is beginning to 
disentangle the specific roles for subsets of aminergic neurons, their target Kenyon cells, and the respectively expressed amine receptors in the acquisition, consolidation, or retrieval of various forms of olfactory memory as well as in motivational control of behavior (e.g., Krashes et al. 2009; Berry et al. 2012; Placais et al. 2012; Perisse et al. 2013; see also Burke et al. 2012); for these aspects too, the roles of dopamine and octopamine apparently transgress the above-mentioned dichotomy. Thus, the striking valence-specificity of driving or impairing aminergic signaling seems to be a property of particular neurons and of their specific target receptors and cellular connectivity, rather than a property of transmitter systems as whole. A similar picture may be emerging for mammals as well (Brischoux et al. 2009; Bromberg-Martin et al. 2010; Ilango et al. 2012; Lammel et al. 2012). Strikingly, even within the aversive domain there may be dissociations on the level of aminergic neurons: Activations caused by aversive air puff or bad tastants in individual midbrain dopamine neurons in the monkey were either not observed at all (most midbrain dopamine neurons are instead activated strongly by unpredicted rewards and reward-predicting stimuli [Schultz 2013]) or were seen only for aversive air puff, or only for bad taste-but not both (Fiorillo et al. 2013b, loc. cit. Fig. 9A) (about a third of the neurons, however, were inhibited by both). This could provide the basis for memories that are specific for the kind, rather than the mere aversiveness, of the punishment employed; indeed, distinct dopamine neurons were activated by cues associated with air puff versus cues associated with bad taste (Fiorillo et al. 2013b, loc. cit. Fig. 9B) (again, about a third of the neurons were inhibited by both). In flies it has so far not been systematically tested whether memories refer to the specific quality of the reinforcer (but see Eschbach et al. 2011); if they did, this would call for a fundamental revision of current thinking on how memories are organized in the Drosophila brain.

\section{Relief-learning}

Compared to punishment- and rewardlearning, relief-learning in Drosophila (Figs. 3, 5) is much less well understood. It was first described by Tanimoto et al. (2004): If an odor is presented after shock, flies subsequently approach that odor, arguably (Box 1) because of its association with the relieving cessation of shock (Figs. 3, 5). That is, a fairly minor parametric change such as inverting event timing during training has a rather drastic qualitative effect: It inverts behavioral valence, such that odor $\rightarrow$ shock training establishes conditioned avoidance, while shock $\rightarrow$ odor training establishes conditioned approach toward the odor.

In a follow-up study, Yarali et al. (2008) demonstrated that after relieftraining, the preference toward the trained odor is indeed associatively increased; this effect does not seem to interact with the innate valence of the odor,

but rather adds on to it. That study also suggested that relief-learning is likely independent of context-shock associations and that it needs more repetitive but less intense training than punishment-learning (Fig. 5; see Box 1 for the theoretical implications of these findings). Namely, relief-learning in Drosophila reaches asymptote after six training trials (together with the given signal-to-noise ratio, this makes relief-learning 10- to 20 -fold more laborious than the standard one-trial version of punishment-learning; note that in all direct comparisons reviewed in this paper nothing but the inter-stimulus interval is varied between punishment- and relief-learning procedures) and is optimal at relatively mild shock intensities. The latter may be because shocks that are too strong induce anterograde amnesic effects, such that a subsequent odor presentation remains unrecognized by the flies, preventing the relatively weak effects of relief-learning. Alternatively, it may be that the more intense the shock, the longer is the aversive state it induces, such that the ensuing relief is further delayed. In that case, the optimal timing of the odor with respect to shock for yielding either type of memory would depend on shock intensity (Bayer et al. 2007). Both of these scenarios may offer perspectives on the nature of

A
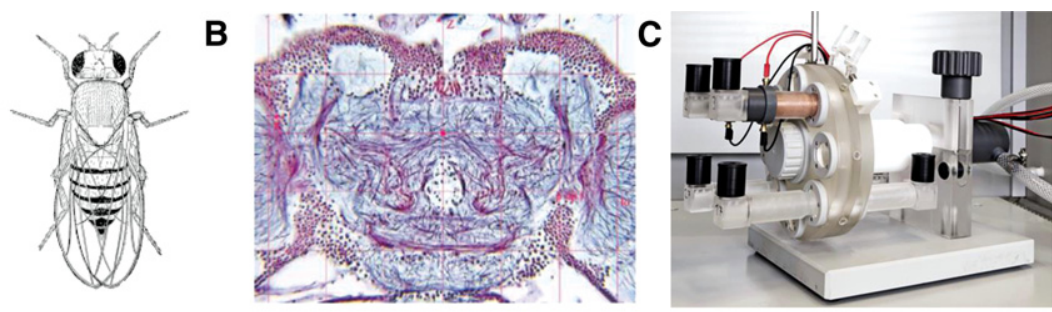

Training

Test

D
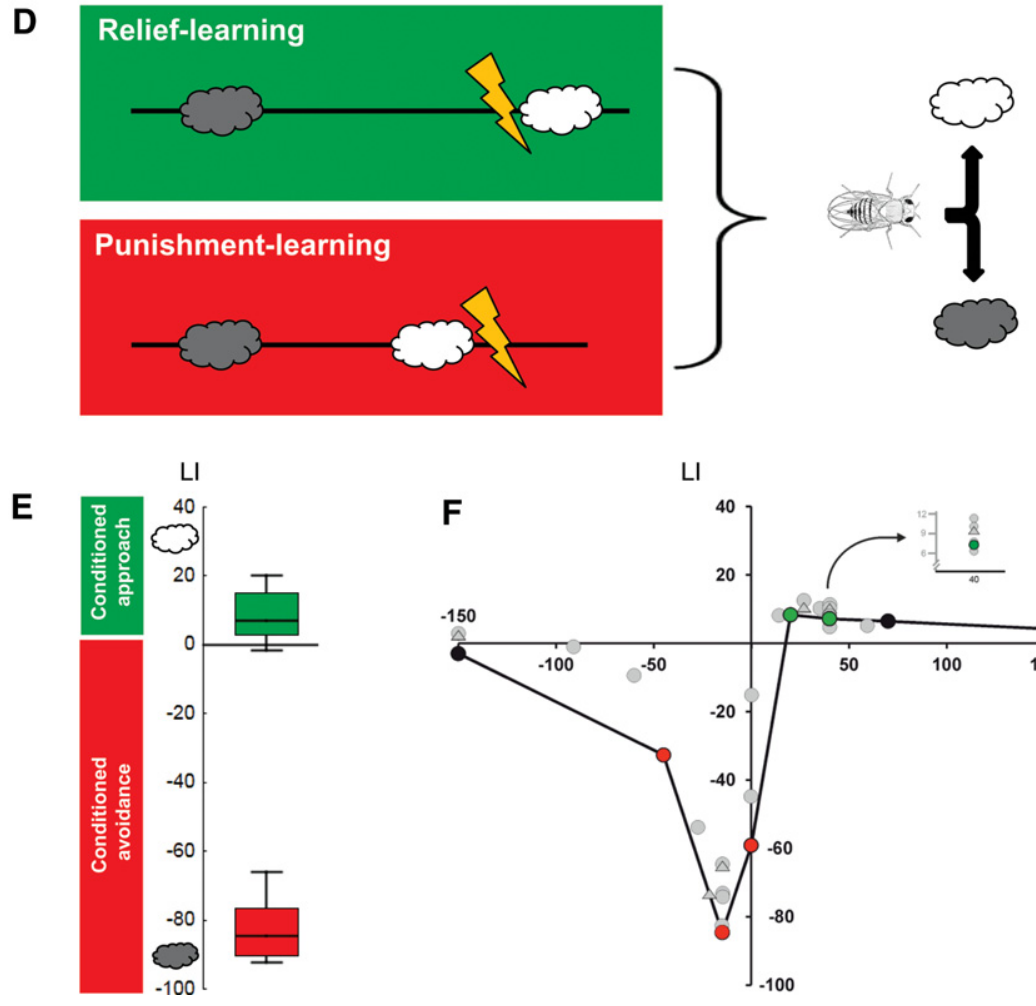

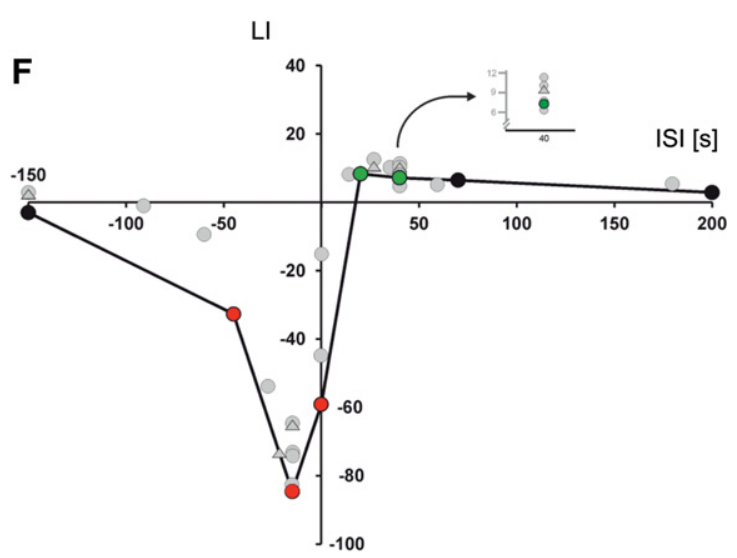

Figure 3. (Legend on next page) 
"trauma" (Box 2) in the sense that massive or mild adverse experiences may induce punishment and relief memories to a lesser or stronger extent.

The temporal pattern of decay of relief-memory differs from both punishment- and reward-memories (Fig. 5; Yarali et al. 2008; Diegelmann et al. 2013b): Over the first $4 \mathrm{~h}$ following training, relief-memory decays much more slowly than punishmentmemory, as is reminiscent of the slow initial decay rate of rewardmemory (Tempel et al. 1983; Schwaerzel et al. 2007; Krashes and Waddell 2008). For longer retention periods, however, only multiple, temporally spaced training trials result in longer-term (24-h) punishment-memory (Tully et al. 1994; Isabel et al. 2004; Diegelmann et al. 2013b), whereas for longer-term reward-memory even a single training trial suffices (Krashes and Waddell 2008; Colomb et al. 2009). For relief-learning, despite using multiple, spaced training trials, Diegelmann et al. (2013b) found no longerterm relief-memory (Fig. 5). Also, unlike both punishment- and reward-learning, relief-learning fails to induce amnesia-resistant memory (Fig. 5; Diegelmann et al. 2013b). If both punishmentand relief-memories were formed in a natural string of events around a painful experience, these findings may be of practical importance: While trying to erase punishment-memory, one may unwittingly also erase relief-memory. Depending on the relative strength of these memories and the relative effectiveness of the treatment, the net effect of such manipulation may be to make the overall mnemonic effect of the experience even more adverse. Again, these conclusions may be of relevance for the understanding of "trauma" and its treatment (Box 2).

In two further studies, the neurogenetic bases of fly relief-learning were investigated: First, the role of the white gene (CG2759) in relief-learning was tested (Yarali et al. 2009b). The white gene product forms one-half of an ATP-binding transmembrane transporter (O'Hare et al. 1984). Its reported cargoes are the signaling molecule cGMP, as well as a heterogeneous set of molecules required for the synthesis of eye pigments and serotonin (Sullivan and Sullivan 1975; Howells et al. 1977; Sullivan et al. 1979, 1980; Koshimura et al. 2000; Evans et al. 2008). The white ${ }^{1118}$ mutation enhances punishment-learning (Diegelmann et al. 2006; Yarali et al. 2009b) and reduces relief-learning (Yarali et al. 2009 b), while leaving unaltered the reflexive avoidance behavior toward the shock. It thus seems that specifically the mnemonic effect of shock, the "takehome message" of the painful event, is more negative for the white ${ }^{1118}$ mutant. Whether this genetic effect in the white ${ }^{118}$ mutant is molecularly related to altered levels of biogenic amines is a matter of controversy (Sitaraman et al. 2008; Yarali et al. 2009b). Interestingly, genetic variance in the human homolog of the white gene (ABCG1) has been related to susceptibility to mood and panic disorders (Nakamura et al. 1999).

Second, Yarali and Gerber (2010) compared relief-learning to both punishment- and reward-learning in terms of sensitivity to manipulations of aminergic signaling. Blocking synaptic output from a subset of dopaminergic neurons defined by the TH-Gal4 driver partially impairs punishment-learning (see also Schwaerzel et al. 2003; Aso et al. 2010, 2012); however, relief-learning remains intact. As for the comparison to rewardlearning, interfering with another set of dopaminergic neurons, which need to provide output for reward-learning to occur (defined by the DDC-Gal4 driver) (Burke et al. 2012; Liu et al. 2012), also leaves relief-learning intact. Furthermore, the $t \beta h^{M 18}$ mutation, compromising octopamine biosynthesis, impairs reward-learning (see also Schwaerzel et al. 2003), but not relief-learning. It therefore appears that relief-learning is neurogenetically distinguishable from both punishment- and reward-learning. Importantly, however, roles of dopamine or octopamine signaling in relief-learning cannot be ruled out because in none of the experiments described was the 
A
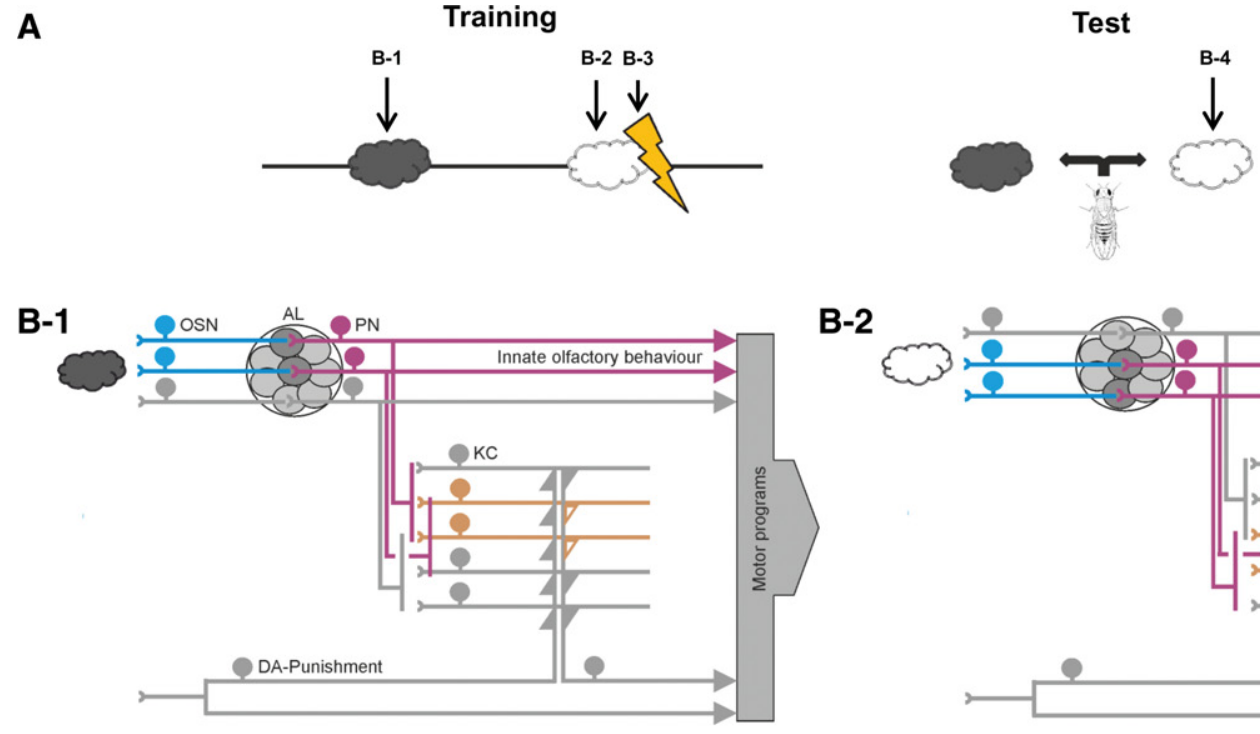

B-2

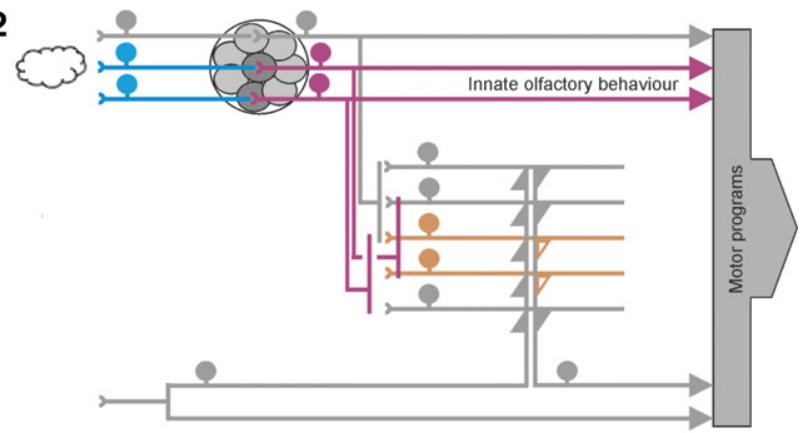

B-3

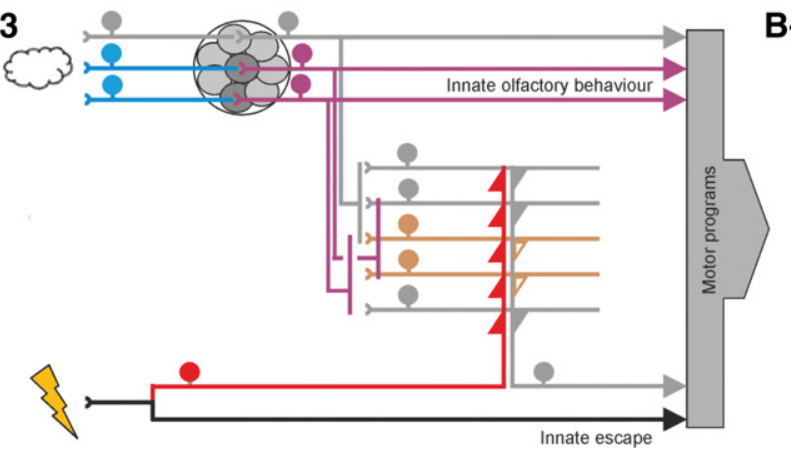

B-4

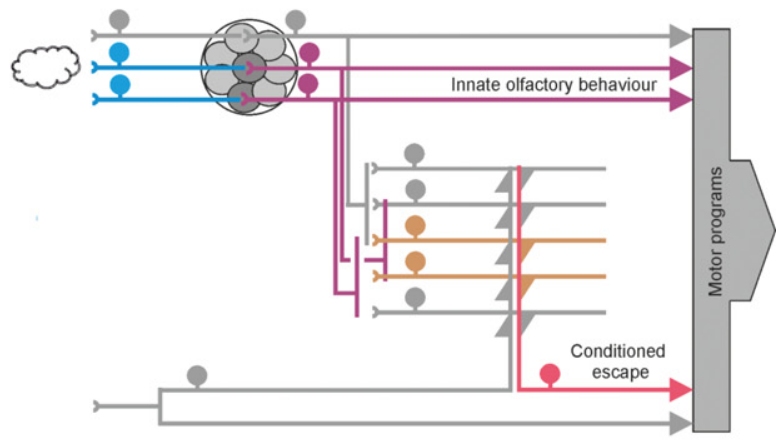

Figure 4. Simplified working model of punishment-learning in Drosophila. (A) Timing of events for punishment-learning, and indication of the time points at which snapshots of activity patterns are displayed in $B 1-B 4$. (B) Snapshots of stimulus-evoked activity during training (B1-B3) and testing (B4). Coloring indicates activity. Please note that both the odors as well as the electric shock activate two pathways each: one to trigger the respective innate behavior and one detour toward the mushroom body Kenyon cells. It is these detour pathways that feature coincidence detection and associative plasticity. Also, please note the combined divergence-convergence connectivity between the projection neurons and mushroom body Kenyon cells. (OSN) Olfactory sensory neurons, (AL) antennal lobe, (PN) projection neurons, (KC) mushroom body Kenyon cells, (DA) a subset of dopaminergic neurons mediating an internal punishment signal. $(B 1, B 2)$ Depending on the ligand profiles of the expressed olfactory receptors and the connectivity within the circuit, a given odor (gray cloud in B1) activates a particular set of olfactory sensory neurons, antennal lobe glomeruli, projection neurons, and mushroom body Kenyon cells. A different odor (white cloud in B2) activates a different pattern of the respective neurons. As for both these odors the animals are experimentally naïve, only innate olfactory behavior is expressed; that is, the output of the mushroom body Kenyon cells (open orange triangles) is not sufficiently strong to activate their postsynaptic partners and thus cannot steer conditioned escape. $(B 3, B 4)$ Coincidence of a dopaminergic punishment signal and odor-induced activity in the odor-specific subset of mushroom body Kenyon cells ( $B 3$ ) (as flies are confined to the training tube, and no behavioral observations are possible [Fig. 3], the integration of innate shock-related escape with innate olfactory behavioral tendencies remains unknown). Coincidence is molecularly detected by the type I adenylate cyclase and arguably enacted, at least in part, by phosphorylation of synapsin and the recruitment of synaptic vesicles for subsequent release. If following this coincidence the previously punished odor is presented again (B4), it can activate a set of thus potentiated output synapses from the mushroom body Kenyon cells (filled triangles), such that conditioned escape is possible. Please note that the interplay of innate and conditioned olfactory behavior (B3) remains distressingly little understood. For clarity, the circuit is numerically simplified and altogether omits a number of neuronal classes including within-antennal lobe interneurons, multiglomerular projection neurons, and a host of modulatory inputs as well as of mushroom body intrinsic feedback neurons (for references to more detailed accounts, see main text; consult Laurent et al. 2001 for possible temporal-coding aspects of olfaction).

respective type of aminergic signaling completely shut off, due to methodological constraints (for a detailed discussion, see Yarali and Gerber 2010). Also, in the tests for octopamine signaling, relief-learning scores in the genetic controls were low, making it practically impossible to ascertain decreases in relief-learning scores; as tendentially increased relief-learning scores may be recognized in the data provided by Yarali and Gerber (2010), however, it still seems fair not to assume a strict requirement for octopamine in relief-learning.

We would like to note that despite the above-mentioned differences across punishment-, reward-, and relief-learning, these three processes are certainly not completely distinct; indeed, much of the sensory and motor circuitry as well as the molecular mechanisms will be shared. Thus, the research problem is rather to understand exactly which processes are shared and which are specific across these three tasks-and how the fly brain is organized to accommodate them.

\section{Possible mechanisms underlying relief-learning}

The relative timing of events is also a key factor in synaptic plasticity. Typically, in spike-timing dependent plasticity (STDP) (for reviews, see Bi and Poo 2001; Caporale and Dan 2008; Markram et al. 2011) a synaptic connection is strengthened when action 
A

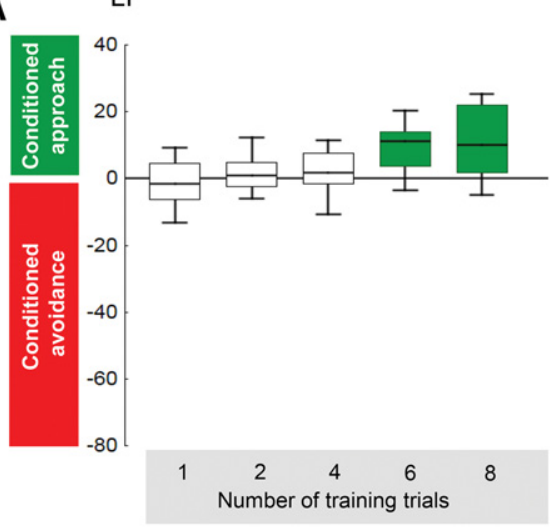

C

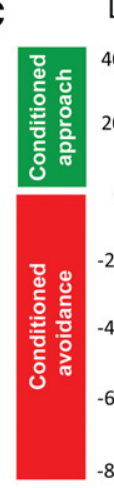

LI

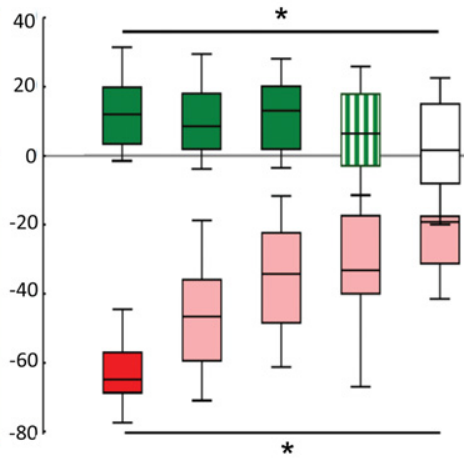

$25 \mathrm{~min} 50 \mathrm{~min} 75 \mathrm{~min} 240 \mathrm{~min} 24 \mathrm{~h}$ Retention period

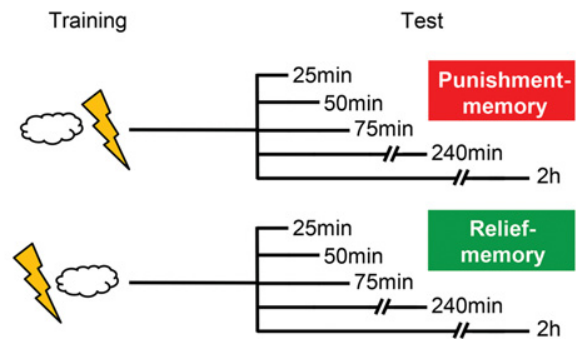

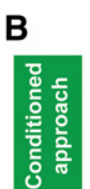
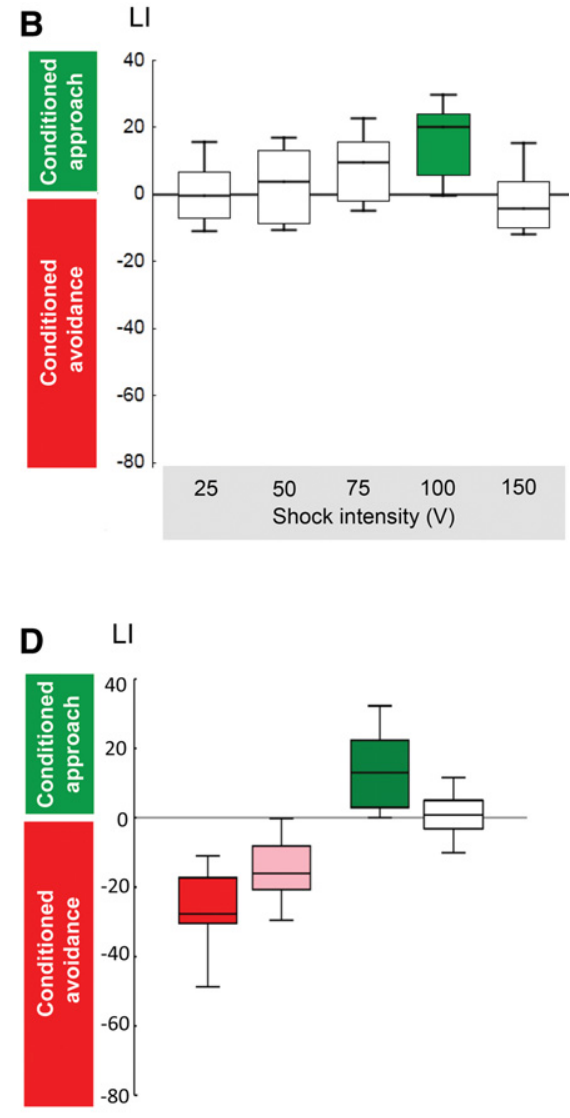

Control * Control * Retention period [120min]

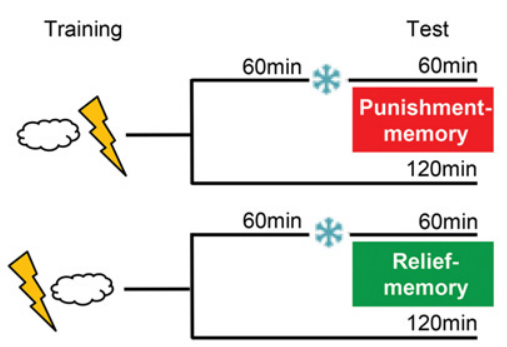

Figure 5. Features of relief-learning in wild-type Drosophila. $(A)$ Relief-learning requires multiple trials. Coloring implies Bonferroni-corrected significance from chance, i.e., from zero. Sample size from left to right: 16, 15, 20, 19, 23. Data taken from Yarali et al. (2008). (B) Relief-learning is strongest at intermediate shock intensities. Coloring implies Bonferroni-corrected significance from chance, i.e., from zero. Sample size from left to right: 8, 7, 12, 15, 7. Data taken from Yarali et al. (2008). (C) Time course of memory decay differs between relief-learning and punishment-learning. Relief-memory scores are stable for $75 \mathrm{~min}$, yet have decayed fully by $24 \mathrm{~h}$ after training. In contrast, punishment-memory scores decay to about half within the first $75 \mathrm{~min}$ and then remain stable. Coloring implies Bonferroni-corrected significance from chance, i.e., from zero. Sample size $N=51,35,46,43,40$ for relief-memory and $N=20$ in all cases of punishment-memory. Data taken from Diegelmann et al. (2013b). (D) Cold-amnesia abolishes relief-memory, but spares about half of punishment-memory scores. Coloring implies Bonferroni-corrected significance from chance, i.e., from zero. Sample size $N=$ 14 in all cases. Data taken from Diegelmann et al. (2013b).

potentials in the presynaptic cell precede those in the postsynaptic cell, while a reverse order of events weakens the synaptic connection.

Given the conspicuous parallelism of STDP on the synaptic level with the timing-dependent switch between punishment and relief-learning in Drosophila, Drew and Abbott (2006) ventured a computational study to establish whether STDP, operating

at the time scale of milliseconds, can indeed lead to behavioral effects on the time scale of seconds. The authors modeled a circuit in which the odor activates a subset of Kenyon cells, whereas the shock excites their postsynaptic partner, which mediates avoidance. For both odor- and shock-induced activity, rather high firing rates were assumed that decay only slowly (several seconds) upon termination of the respective stimulus. Then, the authors implemented an STDP rule, operating at the millisecond-scale (indeed, STDP takes place at the Kenyon cell output synapses, as shown in the locust [Cassenaer and Laurent 2007, 2012]). As long as relatively high spiking rates and relatively slow decay rates are assumed, this model does account for the effect of the relative timing of odor and shock at the behavioral level, which occurs at the scale of several seconds. However, the assumed strong and persistent spiking activity has not been observed in Drosophila Kenyon cells; rather, it turns out that these cells fire strikingly few spikes at the beginning and/or at the end of odor presentation (Murthy et al. 2008; Turner et al. 2008; for moth Kenyon cells, see Ito et al. 2008). Also, it remains unclear whether the shock signal indeed impinges upon the postsynaptic partners of the Kenyon cells. The data so far rather suggest that the Kenyon cells themselves receive a dopaminergic reinforcement signal: Dopamine receptors are enriched in the Kenyon cells (Han et al. 1996; Kim et al. 2003), and restoring receptor function in the Kenyon cells rescues the learning impairment of a dopamine receptor mutant (Kim et al. 2007). Furthermore, synaptic output from Kenyon cells during the training phase has repeatedly been found to be dispensable for punishment-learning (Dubnau et al. 2001; McGuire et al. 2001; Schwaerzel et al. 2003). Altogether, Drew and Abbott's (2006) STDP-based model thus does not embrace the empirical findings particularly well. We note, however, that the STDP rule is sensitive to neuromodulatory effects, as shown for the locust Kenyon cell output synapses (Cassenaer and Laurent 2012), and incorporating such effects may result in more realistic STDP-based models of punishment-, reward-, and relief-learning. In any event, the STDP-based model by Drew and Abbott (2006) does not predict safety-learning as a result of unpaired presentations of odor and shock. Such unpaired-training can, however, have mnemonic consequences: In larval Drosophila unpaired presentations of odor and a sugar reward turn the odor into a predictor of no-reward (Saumweber et al. 2011; Barth et al. 2014; concerning honeybees, see Hellstern et al. 1998 and references therein). Also, given the innate 
BOX 2. Punishment, relief, and "trauma"

Remembering past adverse, punishing events is, in principle, adaptive since it helps us to avoid or to cope with future dangerous situations. However, emotional memories of extremely distressing "traumatic" events can become overwhelming, leading to psychiatric complications such as post-traumatic stress disorder (PTSD). Core symptoms of PTSD are intrusions and flashbacks, i.e., unusually vivid memories of the traumatic event. Such a traumatic event can be criminal victimizations, accidents, combat experiences, or childhood maltreatment (summarized in Nemeroff et al. 2006). While the frequency, type, and intensity of such episodes are critical determinants for developing PTSD, it remains striking that $<30 \%$ of those exposed to comparable sequences of events go on to develop PTSD. There are several personrelated risk factors such as polymorphisms in several genes (e.g., DRD2 or MAO), female gender, and preexisting psychiatric conditions, such as depression and alcohol abuse, as well as ineffective coping strategies. To develop a conceptual handle on PTSD, therefore, not only do the status of the subject and aspects of punishment-learning have to be considered (e.g., genotype and personal history of the subject, graveness of the traumatic experiences, levels of generalization, the temporal dynamics of memory consolidation, retrieval-induced reconsolidation, extinction, and spontaneous recovery), but mechanisms of operant learning as well as nonassociative processes are also likely to be of significance (for discussions, see Siegmund and Wotjak 2006; Riebe et al. 2012).

Such complexity makes it difficult to establish comprehensive experimental models of PTSD. Also, as the graveness of the events is of significance for the switch from adaptive aversive learning to trauma, it is intrinsically problematic to develop such experimental models because this graveness defines the boundaries of what is ethically acceptable in experimental settings, not only in humans but in animals as well. In other words, if the experimental treatment is grave enough to induce PTSD, it may arguably not be ethical, whereas when it remains within ethical bounds, it may not be grave enough to induce PTSD. The existing rodent models of PTSD employ a single exposure to an intensive foot shock or to a predator to model the traumatic experience (e.g., Adamec and Shallow 1993; Siegmund and Wotjak 2007) and are useful for observing and understanding the long-lasting associative and nonassociative symptoms of fear (e.g., conditioned fear of contextual features of the traumatic experience, social anxiety, neophobia, exaggerated startle). Such models should allow investigation into whether such experiences also lead to conditioned relief and whether such conditioned relief impacts "rodent-PTSD."

Regarding PTSD in humans, we find it reasonable to suppose that, though perhaps restricted to an implicit level, there is a moment of relief upon the cessation of a traumatic event and that this may be of mnemonic, psychological, and behavioral significance to the traumatized person. In particular, to the extent that repetitions are "needed" to induce trauma, increasing or broadening of generalization of relieftype memories may be relevant entry points to ameliorate the impact of a first relatively mild such episode and/or to protect the patient in a possible next such episode. Furthermore, one may ask whether the cessation of intrusive flashback memories may cause relief, whether such relief contributes to the maintenance of the disorder or can be exploited in therapy, or whether it may rather complicate therapy if such relief-learning repeatedly happens in therapeutic settings so as to unwittingly induce attachment to these settings. Basic and translational research on punishment- and relief-learning with relatively mild aversive events may therefore also turn out useful with regard to trauma and PTSD. avoidance of odors typically observed in the current paradigm, the attraction to odors after unpaired presentations of odor and shock in adult Drosophila can be understood as reflecting safety-learning (e.g., Niewalda et al. 2011, loc. cit. Fig. S5; Barth et al. 2014).

Alternatively, the event timing-dependent transition between punishment and relief-learning may be rooted in the very molecular mechanism of coincidence detection. It is likely that during punishment-training the type I adenylate cyclase rutabaga (CG9533) acts as a molecular detector of the coincidence between a neuromodulatory reinforcement signal and the odor-evoked activity in the mushroom body Kenyon cells (Tomchik and Davis 2009; Gervasi et al. 2010). Due to this coincidence, in the respective odor-activated Kenyon cells, cAMP would be produced and PKA be activated, leading to the phosphorylation of downstream effectors, conceivably including Synapsin (CG3985). Synapsin phosphorylation would, in turn, allow the recruitment of reservepool vesicles toward the readily releasable pool (for discussion, see Diegelmann et al. 2013a), enabling a stronger synaptic output upon odor presentation after training and eventually leading to conditioned avoidance. Consistent with this scenario, the impairments in punishment-learning by mutations in the rutabaga and synapsin genes are not additive (Knapek et al. 2010); also, in odor-sugar associative learning of larval Drosophila, the impairment of the $s y n^{97}$ mutant cannot be rescued by a transgenically expressed synapsin that lacks functional PKA/CaMKII recognition sites (Michels et al. 2011; for recent data suggesting a role of CaMKII for Synapsin phosphorylation in olfactory habituation, see Sadanandappa et al. 2013).

Could both punishment and relief-learning possibly be accommodated in the same Kenyon cells, based on an event timingdependent, bidirectional modulation of AC-cAMP-PKA signaling? This was explored in a computational study by Yarali et al. (2012). In their model, upon the application of shock-alone, all Kenyon cells receive a shock-induced neuromodulatory signal, which triggers G-protein signaling, consequently activating the adenylate cyclase. As active adenylate cyclase accumulates, the reverse reaction, that is, deactivation of the adenylate cyclase, also takes place. Once shock is over and the neuromodulatory signal has waned, this deactivation of the adenylate cyclase becomes the dominant reaction, leading eventually to the deactivation of all adenylate cyclase molecules. The level of cAMP production caused by such shock-alone stimulation is taken as a "baseline" level and assumed to already potentiate the output from all Kenyon cells to the downstream avoidance circuit. Application of an odor, in turn, raises the presynaptic $\mathrm{Ca}^{2+}$ concentration specifically in the respective subset of model Kenyon cells coding for this odor. Such presynaptic $\mathrm{Ca}^{2+}$ multiplicatively increases the rate constants for both the G-protein-dependent activation of adenylate cyclase and its deactivation (Yovell and Abrams 1992; Abrams et al. 1998). Thus, the net effect of $\mathrm{Ca}^{2+}$ on the adenylate cyclase-dynamics depends on its timing. That is, $\mathrm{Ca}^{2+}$ has no net effect if it arrives long before the neuromodulatory activation of adenylate cyclase has begun, or long after the deactivation of adenylate cyclase has been completed. Note that this model thus also does not predict safety-learning resulting from unpaired presentations of odor and shock, although such learning likely does take place. On the other hand, if the $\mathrm{Ca}^{2+}$ arrives while adenylate cyclase-activation is dominant, it speeds up this activation, whereas if it arrives while adenylate cyclase is predominantly being deactivated, this deactivation is accelerated. Accordingly, in simulated punishment-training the shock-induced neuromodulatory signal activates the adenylate cyclase in all Kenyon cells. Only in those Kenyon cells that code for the particular odor does a rise in $\mathrm{Ca}^{2+}$ coincide with this activation phase, speeding it up. The resulting above-baseline level of cAMP is then assumed to potentiate the output from these Kenyon cells further, beyond 
the potentiation in all Kenyon cells due to the shock-alone, thus enabling the trained odor subsequently to induce conditioned avoidance more readily than other odors. In turn, in simulated relief-training, the odor-induced rise in $\mathrm{Ca}^{2+}$ follows the shockinduced neuromodulatory signal that coincides with the deactivation phase of the adenylate cyclase. Therefore, in the particular odor-coding Kenyon cells, the adenylate cyclase is deactivated faster, resulting in cAMP production below the baseline level. Consequently, the output from these Kenyon cells is less potentiated compared to that of all other Kenyon cells (or compared to a situation where this odor is presented long before or long after the shock), rendering the trained odor less likely to induce conditioned avoidance than other odors. In a choice situation this would result in relative approach toward the trained odor.

Thus, with this model, the timing-dependence of associative function on the behavioral level can be simulated, using $\mathrm{Ca}^{2+}$ as a stand-in for odor, and neuromodulator as a stand-in for shock. The bidirectional regulation of the very coincidence detector, the adenylate cyclase, is used to explain the effect of event-timing on learning. This now invites experimental scrutiny, especially with respect to the requirement for the AC-cAMP-PKA cascade and the Kenyon cells for relief-learning as well as the identity of the respective neuromodulatory signal.

In any event, both Drew and Abbott's (2006) STDP-based model and the adenylate cyclase-based model by Yarali et al. (2012) follow the "canonical" view of short-term mnemonic odor coding in the mushroom body, holding that odors are coded combinatorially across the full array of $\gamma$-lobe Kenyon cells (regarding longer-term memory, this has recently been challenged by Perisse et al. 2013, suggesting that the $\alpha / \beta$ set of Kenyon cells responsible for 3-h memory may be internally "multiplexed" by valence and/or memory strength). That is, punishment and relief-learning rely on the same olfactory representation such that both kinds of learning modify the same Kenyon cell output synapses onto the same downstream circuit (depicted in Fig. 4 for punishment-learning)_but in opposite ways. While this scenario readily accounts for the observed opposite conditioned behaviors of avoidance and approach, more fine-grained investigations into conditioned behavior, and into the anatomy of the mushroom body lobes, may show up the shortcomings of such scenarios: Punishmentlearning may modulate kinds of behavior that relief-learning leaves unaffected and vice versa.

\section{Rat}

\section{Punishment-learning}

Learning that a cue predicts an electric shock is one of the best-studied cases of Pavlovian conditioning in the rat (e.g., for reviews, see Fendt and Fanselow 1999; LeDoux 2000; Maren 2001; Davis
2006; Ehrlich et al. 2009; Pape and Pare 2010). The range of conditioned behaviors toward the learned cue can be understood as making the animal ready for the predicted aversive event and includes protective and defense-related behaviors such as orienting, avoidance, freezing, and potentiation of reflexes including the startle response to facilitate fight-or-flight behavior, as well as autonomic changes such as tachycardia, hypertonia, and an activation of the hypothalamic-pituitary-adrenal axis. Because this syndrome of conditioned effects is similar to the signs of fear in humans, this paradigm is typically referred to as fear conditioning. However, given that for flies there are no arguments for such a comprehensive similarity to human fear, and given that for the present cross-species review we want to use a terminology that is consistent across species, we will use the term punishment-learning instead of fear conditioning for the remainder of this contribution.

In punishment-learning procedures for the rat, the cues to be learned can be visual, as already mentioned, or olfactory, tactile, auditory, or comprising contextual combinations of stimuli from multiple modalities, provided the respective sensory systems are mature (Hunt et al. 1994; Richardson et al. 1995, 2000). Rats
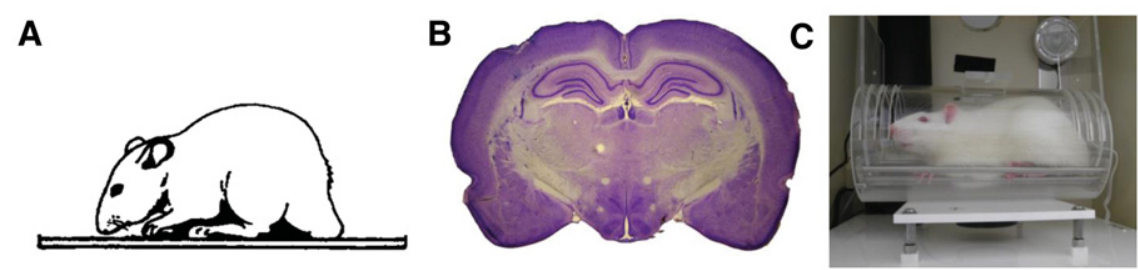

D
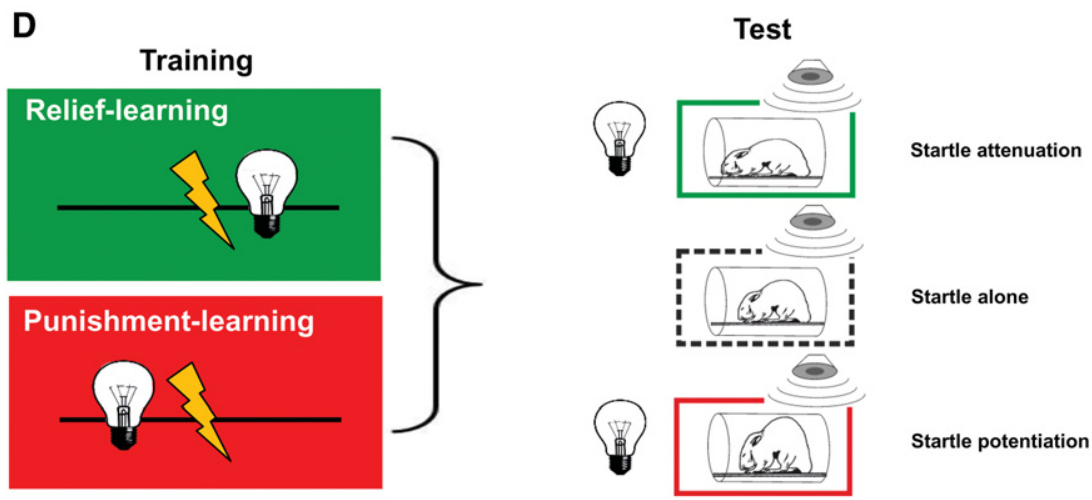

E

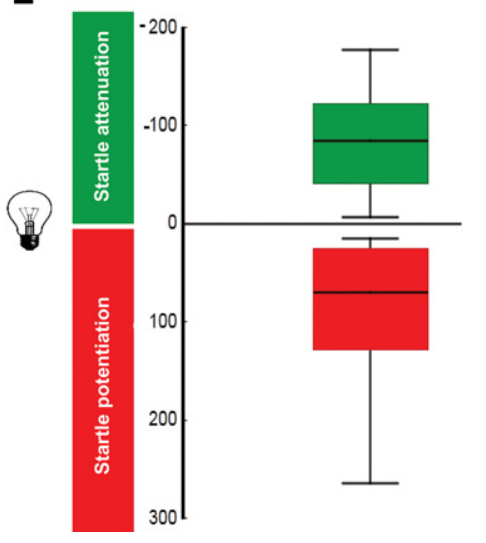

$\mathbf{F}$

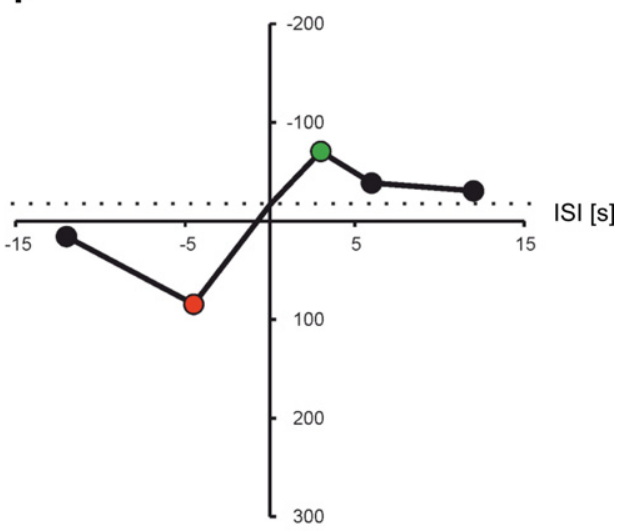

Figure 6. (Legend on next page) 
can learn the association between cue and punishment, which is typically delivered as a foot shock via a metal floor grid, after just one pairing (e.g., Sacchetti et al. 1999); however, more pairings lead to stronger and more stable memories. Further variables which modulate the strength and speed of learning are the intensity of the cue as well as of the shock, and in particular the timing of cue and shock relative to each other: According to the predictive character of the process, learning is not best when shock is applied with the beginning of the cue but, rather, when the shock is applied upon the end of the cue ("delay" procedure). When a temporal gap is left between cue offset and shock onset ("trace" procedure), rats learn less well as the duration of the gap increases. This timing-dependency not only matches that discussed above for the fly, but it is indeed one of the rather few universally observed features of associative learning, on the respectively adaptive time scales ranging from hundreds of milliseconds in the case of eye-blink conditioning to hours in the case of flavor-aversion learning (cf. Rescorla 1988, loc. cit. Fig. 1).

There are different ways to test behaviorally whether the rats have established the association between cue and shock. Here, we focus on the modulation of startle amplitude as a read-out. The startle response (Figs. 6, 8) can be elicited by sudden and intense stimuli (historically, the sound of pistol shots has been used in human subjects [Strauss 1929]) and consists of short-latent muscle contractions collectively serving to protect the organism (especially eyes and neck) and preparing it for subsequent fight-orflight. It is an evolutionarily well-conserved and much-studied reflex (Koch 1999), such that the neural mechanisms of the startle response itself and of its modulations are known in quite some detail in rodents (Fendt and Fanselow 1999; Davis 2006; Davis et al. 2009), monkeys (Davis et al. 2008), and man (Davis et al. 2008, 2009, van Well et al. 2012). The startle response is experimentally elicited by a sudden, very loud noise from a loudspeaker and can be measured by motion-sensitive transducers underneath the floor grid of the measurement apparatus (Fig. 6). This startle response, despite being phylogenetically ancient, is certainly not completely hard-wired: Although the motor programs are qualitatively rather stereotyped, the amplitude of the startle response is higher when the animal is afraid. That is, after animals (or humans) are trained such that they associate a cue with an electric shock, the amplitude of the startle response is increased in the presence as compared to the absence of the cue, an effect called fear-potentiated startle (Brown et al. 1951; Lipp et al. 1994; Koch 1999; Grillon 2002; Davis 2006). It is particularly important in the current context that the startle response has a nonzero baseline; that is, both increases and decreases in startle amplitude can be measured! Indeed, after associating a cue with a reward such as food or rewarding brain stimulation, the amplitude of the startle response is decreased in the presence of the cue (Schmid et al. 1995; Koch et al. 1996; Steidl et al. 2001; Schneider and Spanagel 2008). Thus, as in the case already discussed for flies, the paradigm of startle modulation is bivalent: Under neutral conditions startle is normal, while when expecting something bad startle is potentiated, and when expecting something good startle is attenuated.

Concerning the circuits underlying punishment-learning in rats (Fig. 7), it is well established that the amygdala plays a critical role (summarized in Maren 2001, Ehrlich et al. 2009, and Pape and Pare 2010). The lateral/basolateral part of the amygdala features as a convergence site for cue and shock processing. Information about the cue is carried by projections from the thalamic geniculate nucleus and the sensory cortices, while information about the shock is carried by projections from posterior intralaminar nuclei of the thalamus and caudal insular cortex. During acquisition of the cue-shock association, long-term potentiation of the synapses from the cortical sensory and thalamic geniculate projections to projection neurons within the lateral/basolateral amygdala is induced, thus effectively potentiating the cue's sensory pathway to the lateral/basolateral amygdala (McKernan and ShinnickGallagher 1997; Rogan et al. 1997). Furthermore, it is believed that longterm depression occurs in sensory pathways mediating cues to the lateral/basolateral amygdala whose activity is unor anti-correlated with shock occurrence (Heinbockel and Pape 2000). Thus, when after training the learned cue is presented alone, projection neurons of the lateral/ basolateral amygdala will be activated. These neurons can, in turn, activate projection neurons in the central nucleus of the amygdala. The conditioned behavior is organized via projections from these central amygdala neurons toward the midbrain and the brainstem (Fendt and Fanselow 1999; LeDoux 2000; Maren 


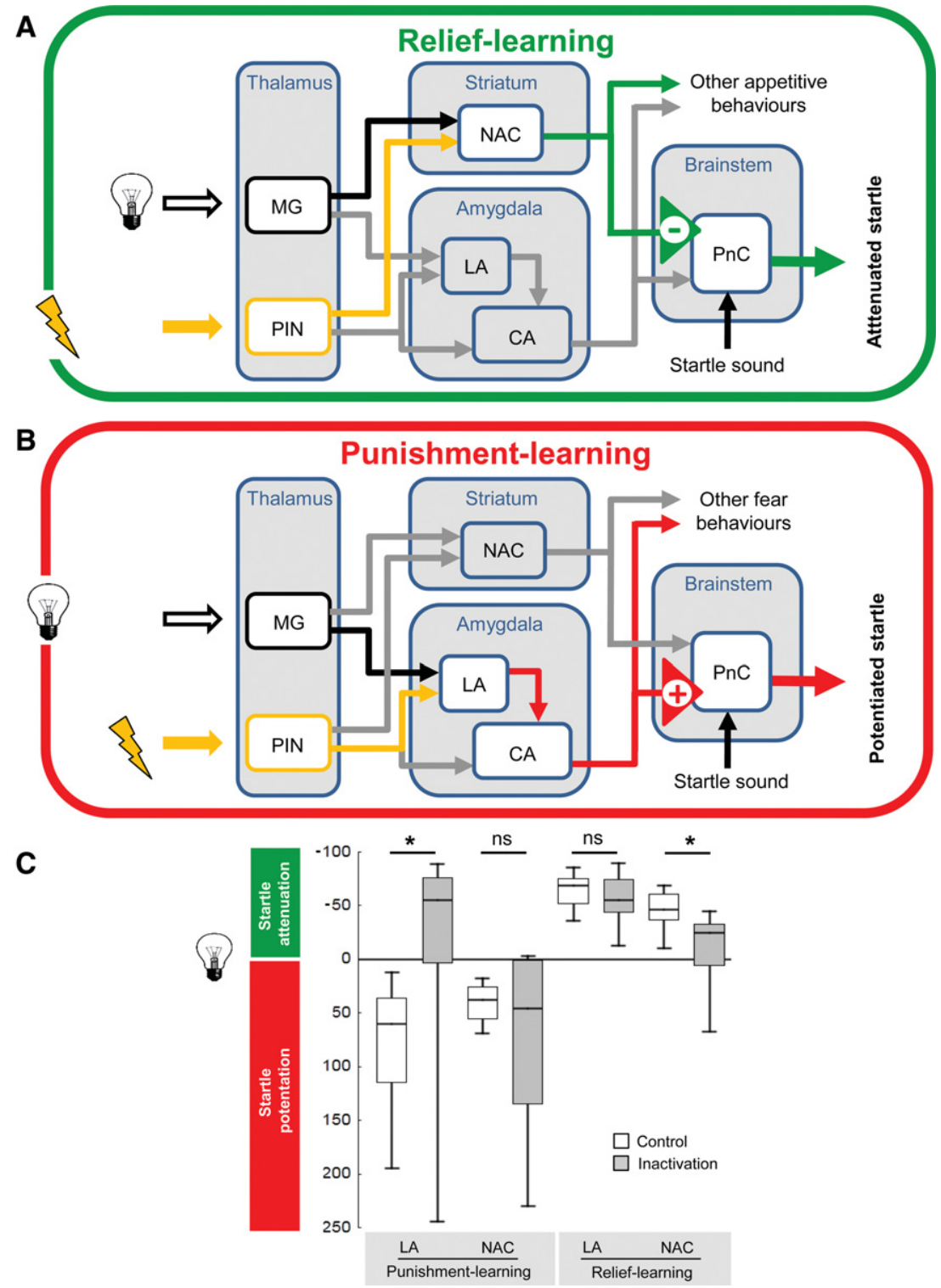

Figure 7. Simplified working model of relief- and punishment-learning in the rat. (A) During relief-learning, the shock is presented first and the light is presented only afterward. This, we propose, leads to memory trace formation by the coincidence of light processing and internal reinforcement processing in the nucleus accumbens (NAC) of the striatum where some neurons are active upon shock offset. Upon testing with the light stimulus, output from the nucleus accumbens is suggested to impinge upon the pontine reticular nucleus $(\mathrm{PnC})$ in the brainstem to mediate startle attenuation. $(B)$ During punishment-learning, the light is presented first and the shock is presented only afterward. This is known to lead to memory trace formation by the coincidence of light processing and internal reinforcement processing in the lateral amygdala (LA). Upon testing with the light stimulus, output from the lateral amygdala, via the central amygdala (CA), also projects to the pontine reticular nucleus $(\mathrm{PnC})$ in the brainstem, but by a pathway that leads to startle potentiation. (MG) Medial geniculate nucleus, (PIN) posterior intralaminar nuclei. (C) Local transient inactivation, using the GABA-A receptor agonist muscimol, of either the lateral amygdala (LA) or the nucleus accumbens (NAC) during the test for conditioned punishment or conditioned relief. Open plots refer to controls injected with saline. Punishment-learning leads to negative conditioned valence and thus is plotted downward (startle potentiation); relief-learning leads to positive conditioned valence and thus is plotted upward (startle attenuation). Inactivation of the lateral amygdala abolished punishment-memory but leaves relief-memory intact; in turn, inactivation of the nucleus accumbens leaves punishment-memory intact yet impairs relief-memory. Sample sizes are N=7-9 per group. Data in C taken from Andreatta et al. (2012).

2001), i.e., the potentiation of startle takes place by direct and indirect projections from the central amygdala to giant neurons within the caudal pontine reticular nucleus that in turn activate spinal motor neurons (Fendt and Fanselow 1999; Koch 1999).
Key observations to support this working hypothesis come from pharmacological inactivation or lesions of the lateral amygdala in rats, which robustly block punishment-learning (Hitchcock and Davis 1986; Helmstetter and Bellgowan 1994; Muller et al. 1997). Importantly, the functional integrity of the lateral amygdala is necessary for both establishing and remembering cueshock associations (Muller et al. 1997). It has further been revealed that longterm potentiation of the thalamic/ cortical input to the lateral/basolateral amygdala underlying punishmentlearning is NMDA receptor-dependent (Miserendino et al. 1990; Maren et al. 1996) and is controlled by a complex network of GABA-ergic interneurons (summarized in Ehrlich et al. 2009). Activity of these interneurons can be modulated by several neuropeptides as well as by serotonin, noradrenalin, and acetylcholine.

As briefly mentioned above, the amplitude of startle is not only potentiated by learned punishment but can also be attenuated by cues associated with reward. Such conditioned "pleasure-attenuated startle" was first established by Schmid et al. (1995): In their study, a light cue was repeatedly paired with a food reward. After this association was learned, startle amplitude was attenuated by the light cue. This effect can be blocked by lesions of the dopamine neurons within the nucleus accumbens but not by lesions of the amygdala (Koch et al. 1996). This first study on the neural basis of pleasure-attenuated startle suggested that the mesoaccumbal system that is generally crucial for reward-related learning (for reviews, see, e.g., Cardinal and Everitt 2004; Schultz 2013; but see also Bromberg-Martin et al. 2010; Ilango et al. 2012; Lammel et al. 2012) is also important for pleasure-attenuated startle.

Several studies have also demonstrated that the nucleus accumbens is able to modulate punishment-learning. For example, temporary inactivation of the nucleus accumbens by local injections of tetrodotoxin or of the muscarinic agonist carbachol blocks the acquisition and expression of punishment-learning (Schwienbacher et al. 2004, 2006; Cousens et al. 2011). However, manipulating dopamine signaling within the nucleus accumbens has no effect on punishment-learning (Josselyn et al. 2005; Schwienbacher et al. 2005). This is supported by a recent study showing that the GABA-ergic but not the dopaminergic neurons in the ventral tegmental area (projecting to the nucleus accumbens) are activated by punishment (Cohen et al. 2012). 


\section{Relief-learning}

For the establishment of a relief-learning paradigm on the basis of the startle response in rats (Andreatta et al. 2012), it seemed significant that relief-learning in flies works best with a relatively long gap between electric shock offset and cue onset (5-25 sec) (Tanimoto et al. 2004; Yarali et al. 2008). In the vertebrate literature this kind of procedure has been called "backward-trace" conditioning; for the remainder of this contribution, however, we use the term relief-learning instead, in order to apply a consistent nomenclature across the three species covered. In any case, such a relief-learning type of procedure has been employed relatively rarely: Often punishment and cue have a coincident onset, but the cue outlasts the punishment by a long time (Siegel and Domjan 1974; Walasek et al. 1995), or a rather short cue is presented during or after a rather long aversive stimulus (Heth and Rescorla 1973). Also, the question investigated has mostly been whether such a relief-learning type of procedure leads to less strong learning than punishment-learning. However, there have been few studies directly suggesting a positive valence of the learned cue after relief-learning types of procedure: Walasek and colleagues (1995) used a 1-sec shock and a 1-min cue which had simultaneous onsets such that the cue outlasted the punishment by $59 \mathrm{sec}$. In a subsequent test session, the authors observed an increase in bar pressing for food during the presence of the cue (compared with bar pressing under baseline conditions), which was interpreted as "conditioned safety" (see Box 1). In contrast, punishment-learning (i.e., presentation of the 1-sec shock at the end of the 1-min cue) in this paradigm resulted in a strong suppression of bar pressing. This suggests that also in rats changes in the relative timing of cue and punishment do more than affecting whether and how much learning occurs, but rather can affect the valence of the respective mnemonic effect (for a related finding see also Smith and Buchanan 1954). A different approach was used by Navratilova et al. (2012): The authors investigated tonic post-surgical pain and induced relief by pharmacological treatment of that pain. Using a place preference/avoidance apparatus, such treatment was paired with one compartment of the apparatus whereas the other compartment was paired with a placebo treatment. In a subsequent test session, the animals preferred the compartment that had been paired with the pain-relief treatment.

Andreatta et al (2012) decided to use the modulation of the startle response as a behavioral measure to compare punishment- and relief-learning because it can be modulated bivalently (Koch 1999); that is, negatively valenced cues, established by punishment-learning, increase startle amplitude (Brown et al. 1951), whereas positively valenced cues, established by cue-reward associative training, decrease startle amplitude (Schmid et al. 1995). The relief-learning protocol was matched closely to the established punishment-learning protocol (i.e., 15 pairings of a 5-sec light and a $0.5-\mathrm{sec}, 0.8-\mathrm{mA}$ electric foot shock), and varied only the inter-stimulus interval (ISI, defined as the time interval from shock onset to light onset) (Fig. 6): Different groups of rats received a relief-learning protocol such that the onset of the electric shock preceded the onset of the 5-sec cue (denoted as positive ISIs: 3, 6, $12 \mathrm{sec}$ ). In addition, groups were included that underwent punishment-learning with a delay (ISI: $-4.5 \mathrm{sec}$ ) or a trace procedure (ISIs: $-12 \mathrm{sec}$ ). Last, but not least, control groups received either the cue but no electric shock at all, or cue and electric shock at randomized ISIs. In these control groups it was observed that, relative to the startle-alone testing condition, startle is slightly decreased when the cue was present (in Fig. 6, bottom right, the stippled line corresponds to the mean across these control groups and is referred to as the "baseline" in the following). Interpretations of this baseline level might be that it represents an unconditioned distraction effect of the light stimulus on startle, and/or that a mild degree of conditioned safety was induced. In any event, as the cue is moved in time toward shock onset, startle amplitude increases (Fig. 6). As the cue is moved past the shock, however, this effect is reversed and startle amplitude decreases. Importantly, for even longer gaps between shock and cue, startle amplitude returns to baseline levels (Andreatta et al. 2012). Thus, with respect to startle modulation as a measure, the cue has acquired negative conditioned valence with an ISI of $-4.5 \mathrm{sec}$, but positive conditioned valence with an ISI of $3 \mathrm{sec}$; we refer to these effects as punishment- and relief-memory, respectively.

\section{Nucleus accumbens and amygdala are respectively required for relief- and punishment-memory}

Given that relief-learning in a startle paradigm can be demonstrated in the rat, Andreatta et al (2012) asked what its neuronal underpinnings are. A way to probe whether a brain structure is acutely required for a particular behavior is by temporarily inactivating it. This can be done by optogenetic tools (for the rat, see Zalocusky and Deisseroth 2013), or by local microinjections of drugs inactivating neuronal firing. A suitable drug for these purposes is muscimol, a GABA-A receptor agonist, a method previously applied to a number of different brain structures and behaviors (e.g., Fendt et al. 2003; Schulz et al. 2004; Müller and Fendt 2006). Notably, these local injections silence neural activity quickly but are remarkably transient $(\sim 120 \mathrm{~min})$ (Martin 1991).

Given that relief-learning, just like reward-learning, manifests itself as a decrease in startle in the presence of the learned cue, it seemed plausible that brain structures concerned with reward-learning are required for relief-learning as well. The usual first suspect here is the nucleus accumbens, because, like its human terminological counterpart, the ventral striatum (which, however, includes the olfactory tubercle), it is a critical brain structure for organizing learning and behavior in the appetitive domain (Ikemoto and Panksepp 1996, 1999; Berridge and Robinson 1998; Cardinal and Everitt 2004; Schultz 2013). Indeed, the decrease in startle amplitude supported by a reward-associated cue (Schmid et al. 1995) can be blocked by lesions of the nucleus accumbens (Koch et al. 1996).

To test for a role of the nucleus accumbens in relief-memory, cannulas aiming at the respective region were chronically and bilaterally implanted. After recovering from surgery, the animals underwent the relief-learning procedure, without any injections. One day later, muscimol was injected to acutely inactivate the nucleus accumbens, and the ability of the learned cue to modulate the startle response was tested. It turned out that under such accumbal inactivation the learned cue does not support startle attenuation beyond baseline (see Fig. 7). In contrast, silencing the nucleus accumbens did not prevent startle potentiation after punishment-learning. In turn, performance after punishment-learning was abolished by silencing the lateral/basolateral amygdala, a procedure which leaves the performance after relief-learning unaffected. Thus, there is a double dissociation between the requirement of the nucleus accumbens and lateral/ basolateral amygdala for memory after relief-learning or after punishment-learning, respectively (Andreatta et al. 2012). Notably, the "signature" of relief-memory thus corresponds to rewardmemory.

It is important to note that the above experiment specifically tested for effects on the expression of memory, not for effects on the acquisition process. Thus, the reviewed findings raise the question of the role of the nucleus accumbens during training, i.e., during the acquisition of relief-memory, as well as of the task-relevant pathways from the nucleus accumbens onto the 
startle pathway, potentially including the ventral pallidum and/ or the pedunculopontine tegmental nucleus (Koch 1999). A perhaps more immediate question was whether similar neuronal dissociations of punishment- and relief-memory with regard to amygdala and nucleus accumbens are found in humans as well.

\section{Humans}

\section{Punishment- and reward-learning}

In humans too, punishment-learning is most frequently studied in Pavlovian differential conditioning paradigms: For example, a geometrical shape such as a square is presented prior to a mild electric shock (individually calibrated to be mildly painful), while another stimulus, e.g., a triangle, has no such consequence. After several trials of training, punishment-memory can be observed on physiological, behavioral, and verbal levels (see below). Rewardlearning is studied less frequently in humans because sufficiently strong primary rewards are not easily implemented. What has been employed are pleasant odors (e.g., Hermann et al. 2000; Gottfried et al. 2002), pleasant tastants (e.g., O'Doherty et al. 2003), drugs activating primary-reward circuitry (e.g., Winkler et al. 2011), money as a secondary reward (e.g., Knutson et al. 2001; Kirsch et al. 2003), or points worth money as a tertiary reward (e.g., Kahnt et al. 2012).

In humans, as in rats, measures of both physiological parameters (e.g., heart rate, skin conductance response) and of overt behavior (e.g., startle modulation) are used to assess the effects of punishment-learning. Sweating determined as an increase in the skin conductance response is the most frequently used physiological measure: Punishment-associated stimuli trigger enhanced skin conductance responses which increase with the aversiveness of the expected punishment (e.g., Wolter and Lachnit 1993). Important in the current context, however, is that reward-associated stimuli can trigger increases in skin conductance too (e.g., Amrhein et al. 2004; Winkler et al. 2011). Thus, the skin conductance response is a measure of arousal rather than of conditioned valence (see Lang et al. 2000). In humans as well, to specifically measure conditioned valence after punishment-learning, modulations of the startle reflex can be used (see Lang et al. 1990, 2000; Grillon and Baas 2003; Glotzbach-Schoon et al. 2013). Studies of human startle refer to the very rapid wholebody syndrome of postural changes (Fig. 8) as well as the closure of the eyes and accompanying changes in facial expression first described upon shooting a pistol (Strauss 1929; Landis and Hunt 1939) (these early works use the German word "Zusammenschrecken"). Indeed, Woodworth and Schlossberg (1956) suggested that "the most [...] convenient stimulus seems to be shooting a 22-caliber blank cartridge." Contemporary experimental settings instead prefer a short white noise with a sudden onset (e.g., 95-105 dB, $50 \mathrm{msec}$ ) presented via headphones. It was recognized early on (Landis and Hunt 1939) that the most reliable way to quantify startle is to focus on the eye closure component by means of the electromyogram of the musculus orbicularis oculi (Fig. 8; Blumenthal et al. 2005). Alternative ways of eliciting startle responses in humans are via cutaneous (i.e., mechanical stimulation to the forehead by a tap, air-puff, or mild electric shock) or visual stimulation (Blumenthal et al. 2005), while alternatives to measuring eye-blink by electromyograms are to use photoelectric or potentiometric measures (Berg and Balaban 1999; Dawson et al. 1999). In addition, startle entails postural (see above), autonomic (e.g., Hamm et al. 2003a), and electrocortical (e.g., Schupp et al. 1997) responses serving to make the subject ready for an imminent fight-or-flight situation, as well as modulations of the postauricular reflex (e.g., Benning et al. 2004; Franklin et al. 2013a) (note that the latter can reveal positive valence by increased ampli- tude). In humans, as in rats, the amplitude of the startle response is increased in the presence of a shock-associated or an aversive stimulus (Lang et al. 1990; Grillon and Baas 2003; Andreatta et al. 2010; Norrholm et al. 2011). In turn and important in the current context, numerous studies have revealed that startle is decreased by stimuli associated with reward or pleasure (e.g., Geier et al. 2000; Skolnick and Davidson 2002; Conzelmann et al. 2009), although there is a lack of pure reward-conditioning studies with the startle response as a dependent measure. The only such study we are aware of used a visual cue and a monetary reward in a reaction time task but failed to find an effect of the trained cue on startle responses (Lipp et al. 1994). In any event, in humans too the startle response is a bivalent measure: Its potentiation or attenuation can indicate negative or positive conditioned valence, respectively.

In addition to what is possible in rats (and flies, of course), humans can be assessed for their explicit, verbal valence of the conditioned stimulus. This is typically done by asking participants to rate their feeling toward the conditioned stimulus on a scale from "emotionally negative" to "emotionally positive." After conditioning, compared to before training, humans normally rate punishment-associated stimuli as more "emotionally negative" (e.g., Andreatta et al. 2010) and reward-associated stimuli as more "emotionally positive" (Cox et al. 2005). Obviously, such explicit measures of valence are possible only in humans as they are influenced by aspects of human nature that we do not conventionally need to reckon with in rats or flies, such as contingency awareness and reflectivity (see Hofmann et al. 2010). These topdown influences and their interaction with bottom-up processes are captured by dual process theories (e.g., Strack and Deutsch 2004) proposing that human behavior is the result of the integrated operation of impulsive and reflective processing. The reflective system organizes behavior intentionally, that is via decision processes based on knowledge about the value and the probability of behavioral consequences, while the impulsive system operates largely independently of a person's intention or goal. Even so, the impulsive system is thought to generate experiential corollaries, yet these are much less nuanced as compared to the reflective system. Normally, impulsive and reflective processes are well integrated and concordant and jointly organize behavior: Within dual-process theories, the increase or decrease in startle amplitude after punishment- or reward-learning reflects impulsive valuation, while the ratings of the conditioned stimuli track a concordant reflective process. However, as the discussion below will show, under some conditions one has to reckon with discordance among these systems.

The neuronal substrates of punishment-learning and startle potentiation are strikingly similar in man, monkey, and rat, arguably because the underlying circuitry and its modulation are evolutionarily ancient and conserved (see Lang et al. 2000; Davis et al. 2008, 2009). Functional magnetic resonance imaging has confirmed amygdala activity triggered by punishment-associated stimuli as compared to neutral stimuli (e.g., Büchel et al. 1998; LaBar et al. 1998), even if subjects were not aware of stimulus presentation due to masking (Morris et al. 1998). In addition, insula and anterior cingulate cortex were found by most studies to be involved in punishment-learning (for review, see Sehlmeyer et al. 2009). The necessity of the amygdala for punishment-learning in humans is also confirmed by studies examining patients with specific lesions. The seminal study of Bechara et al. (1995) revealed a double dissociation by showing that a patient with bilateral amygdala lesions did not acquire conditioned autonomic fear responses but had declarative knowledge of contingencies, while a patient with bilateral hippocampus lesions failed to learn contingencies but did acquire conditioning. Further studies with amygdala-lesioned patients revealed that these patients do not show startle potentiation either in response to punishment itself 
(Angrilli et al. 1996) or to punishment-associated stimuli, even if they acquire declarative knowledge of contingencies (Weike et al. 2005). In turn, punishment-associated stimuli can cause an increase in startle in subjects with intact amygdalae yet unaware of stimulus presentation due to cortical blindness (Hamm et al. 2003b). Thus, startle potentiation, an implicit measure of conditioned valence after punishment-learning, engages and requires the amygdala, and can take place without contingency awareness and without concordant explicit valuation.

The neuronal substrates of human reward-learning studied by functional magnetic resonance imaging include the ventral striatum (which in humans includes the nucleus accumbens) and the orbitofrontal cortex: Gottfried et al. (2002) paired three neutral faces with pleasant, neutral, or unpleasant odors and found that appetitive olfactory learning led to activity in the medial orbitofrontal cortex and nucleus accumbens as well as in the amygdala. O'Doherty et al. (2002) examined brain activity elicited by visual stimuli previously paired with either a pleasant sweet taste, a moderately aversive lowsalt taste, or no taste. When anticipating reward, activity in the ventral striatum and orbitofrontal cortex was found (for a related finding using monetary reward, see Kirsch et al. 2003); in addition, activity in the amygdala was reported under such conditions. Of these activations, only orbitofrontal cortex activation, arguably in another region, was seen upon the actual delivery of reward (for a report confirming this double role of the orbitofrontal cortex, using a monetary reward, see Cox et al. 2005). Perhaps more important in the current context, the only regions activated in accordance with an appetitive prediction error signal, that is the difference between expected and received reward, are the ventral striatum and orbitofrontal cortex (O'Doherty et al. 2003). Thus, although studies on the necessity of these regions in human primary-reward learning are lacking (but see, e.g., Bechara et al. 1999; Tsuchida et al. 2010) and although the boundary conditions for the engagement of the amygdala in particular still need to be better understood, the underlying circuitry in man may well turn out to be very similar to that in the rat in the case of reward-learning too.

\section{Relief-learning}

In order to fully appreciate the mnemonic consequences of an adverse event such as an electric shock, Andreatta et al. (2012, 2013) decided to test for relieflearning in humans as well, using a paradigm as closely related to the studies in the rat as possible. Two groups of subjects underwent discrimination learning of visual geometrical shapes, one of which became associated with moderately painful electric shocks. What differed between the groups was the relative timing of the visual stimuli and the shocks (Fig. 8): Either one visual shape preceded
A
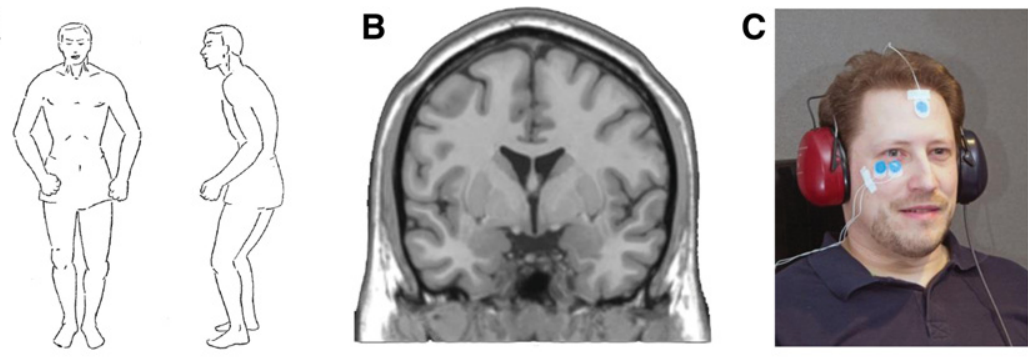

Training
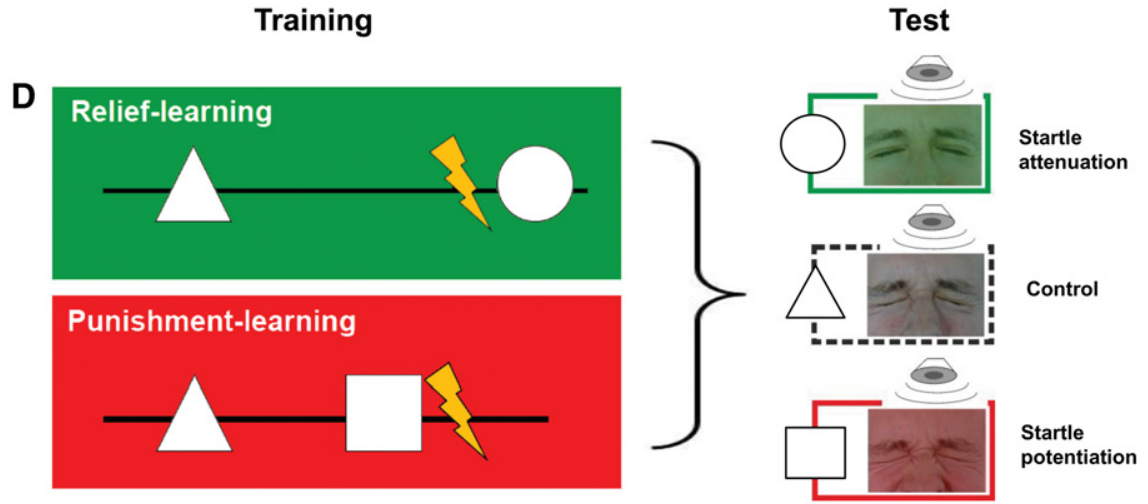

E

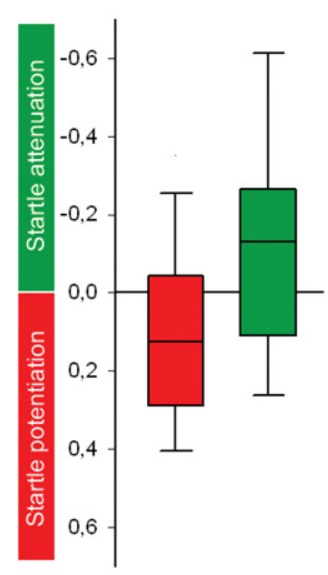

F

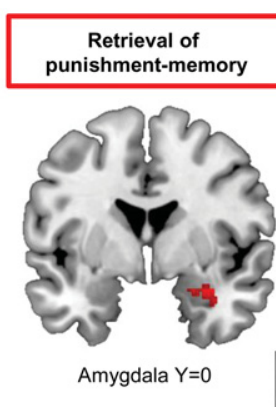

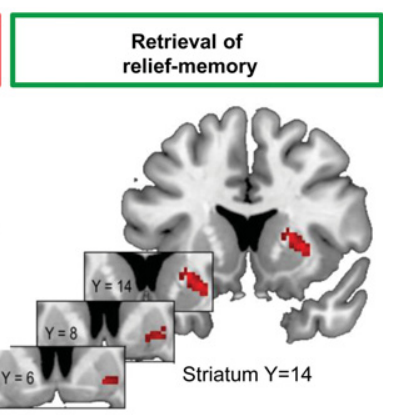

Figure 8. (Legend on next page) 
valence led to the question whether in humans the cortical "footprint" of the learned visual stimulus would be punishmentlike or reward-like, and would thus correspond to explicit or implicit valence judgments. It was found (Fig. 8) that after punishment-learning the learned stimulus activated the amygdala as ing it activated the striatum, i.e., part of a reward network (Andreatta et al. 2012). Thus, in the case of punishment-learning there was a concordance between neural activation, implicit valence, and explicit valence of the learned stimulus. In contrast, after relief-learning the negative explicit valence of the learned stimulus appeared discordant with its reward-like neuronal signature and its positive implicit valence. Notably, after both punishment- and relief-learning an activation of the insula was found (Andreatta et al. 2012). Given that humans explicitly judged both punishment- and relief-conditioned cues as emotionally negative in that study, it is tempting to speculate that the insula is involved in the generation of emotional valence experience (see also Craig 2009) and/or in the experience of excitement independent of valence (Elliott et al. 2000). Recently, a follow-up study (Andreatta et al. 2013) suggested that both the nature of the task as a between- versus a within-subject task and the predictability of the shock modify explicit valence in relief-learning: In a newly introduced within-subjects design, both implicit and explicit valence measures after relief-learning were positive if shock occurrence was predictable. These findings call for a full clarification of the experimental boundary conditions, causes, and psychiatric implications of the observed dissociation between explicit and implicit valence of stimuli associated with relief.

We note that previous studies, although related, used approaches critically different from the relief-learning approach which is the focus of the present review (see also the discussions in Riebe et al. 2012; Kong et al. 2013): Seymour et al. (2005) examined brain responses triggered by stimuli predicting a reduction of tonic pain, Leknes et al. (2011) used a procedure involving the part of a conditioned fear network; in contrast, after relief-learn-

omission of a painful stimulus, and Kim et al. (2006) as well as Levita et al. (2012) studied brain responses during instrumental avoidance of an aversive outcome. Interestingly, reward centers of the brain, i.e., ventral striatum and orbitofrontal cortex, seem to be implicated in all these cases (see also the discussion of the role of these activations in active avoidance learning in Ilango et al. 2012). To study the unconditioned implicit valence of pain offset itself, Franklin et al. (2013a) presented the startle noise immediately after a painful stimulus and measured both the eyeblink and the post-auricular component of the startle response. Startle eye blink was reduced and startle post-auricular reactivity enhanced, arguing not only for a reduction in negative affect but for a genuinely positive affective component several seconds after pain offset. Lastly, Fujiwara et al. (2009) implemented relief in a very different, arguably higher-order sense: Subjects were informed post hoc whether their actual choice had yielded them a better ("relief") or worse ("regret") monetary feedback than if they had made an alternative choice. Under thus-defined relief conditions, activity in anterior ventrolateral prefrontal cortex was observed; notably, this held true for relief cases implemented by means of both more gain and less loss.

In any event, on the basis of the reviewed findings, we propose as a working hypothesis that pain offset activates at least parts of the accumbal reward circuitry and that these activations induce relief-learning. The learned cue is thus endowed with the capacity to trigger conditioned relief, which is entangled with the activity of much of that same circuitry. Consistent with this working hypothesis, firing of dopaminergic neurons as well as the hemodynamic activity of their target regions, such as the ventral striatum, can be increased not only by reward (for review, see Schultz 2013) but also by the reduction (Seymour et al. 2005) or upon the termination (Becerra and Borsook 2008; Brischoux et al. 2009; Fiorillo et al. 2013a,b) of an adverse event. Such offset-activation is particularly obvious when the end of the adverse event is indeed clearly defined in time, as is the case for air puff but arguably not for taste cues such as salty and in particular bitter (Fiorillo et al. 2013b, loc. cit. Fig. 2A). Whether the omission of punishment activates these neurons as well is a matter of controversy (e.g., Leknes et al. 2011; Fiorillo 2013; Fiorillo et al. 2013a,b).

Our working hypothesis must not be construed as equating relief with reward (indeed in flies at least considerable discrepancies are observed: see section "Fly"); rather, we argue that some of the neuronal footprint is shared between relief and reward, prompting the question how far these commonalities extend, both in the neuronal and in the psychological domain - and how the differences between relief and reward are neuronally and psychologically structured. stimulus. Note that the experimental role of the geometrical shapes is counterbalanced across subjects. (E) Experimental data showing relief- or punishment-memory, dependent on the relative timing of the visual stimulus and shock during training. As in Figure 6, positive conditioned valence ("Good") is plotted toward the top of the $y$-axis indicating the degree of startle attenuation; in turn, startle potentiation is plotted toward the bottom of the $y$-axis in order to display negative conditioned valence ("Bad") toward the bottom. The sign of the startle modulation is presented as, respectively, negative or positive, because the actual behavior of the subjects consists of less or more startle, respectively. Box plots show the median as the bold middle line, and the $25 \% / 75 \%$ and $10 \% / 90 \%$ quantiles as box boundaries and whiskers, respectively. Data taken from Andreatta et al. 2010, sample sizes are $N=34$ and $N=33$ for the punishment- and the relief-learning groups, respectively. $(F)$ After punishment-learning, the learned visual stimulus induces activation of the right amygdala (left panel), but not of the striatum. In contrast, a relief-conditioned visual stimulus induces activation of the right striatum (right panel), but not of the amygdala; striatum activation extends to the ventral striatum/nucleus accumbens. Both the punishment- and the relief-conditioned stimulus induce activation of the left insula as well (not shown). From Andreatta et al. (2012), sample sizes are $N=14$ for both the punishment- and the relief-learning groups.

\section{Relevance for defensive behavior: extending the threat-imminence model to post-strike}

Faculties such as punishment-learning have evolved because of their benefits to survival, but of course there are few electric shocks in nature-except perhaps lightning or the defense systems of electric fish. Of greater concern are, for example, predators, parasites, "armed" 
insects, such as mosquitos, ants, or bees, competitors, physical events such as forest fires, as well as irritant, toxic, or, in the case of flies, even predatory plants. In each case, it is adaptive to learn the cues predictive of the threat in order to gain time for deciding on the most appropriate action and/or bodily preparing for it. Such coping behavior includes risk assessment, avoidance/ flight, and approach/fight. Indeed, according to the threatimminence model (Fanselow 1994), defensive behavior in ratsand arguably in humans as well (see, e.g., Löw et al. 2008)—is organized in three stages, depending on the temporal and spatial proximity of threat (see also Blanchard and Blanchard 1989): pre-encounter, post-encounter, and strike phase. If the subject registers an increased likelihood of threat in the preencounter phase, this results in increased general alertness, undirected search behavior, orienting, and risk assessment; this phase in humans is entangled with feelings of anxiety. The postencounter phase is characterized by freezing, reflex potentiation including startle, and selective attention to the encountered threat (interestingly, the silence that ensues upon the cessation of movement during freezing may, in turn, be a signal for threat to conspecifics [Pereira et al. 2012], in particular in combination with ultrasonic distress vocalizations emitted into this silence [Wöhr and Schwarting 2013]). The strike phase is associated with directed fight/flight behavior; in humans both the postencounter and strike phase are characterized by the emotion of fear. While it is unknown which brain structures mediate the pre-encounter phase, the amygdala and the ventral periaqueductal gray are critical for the post-encounter phase, and the dorsal periaqueductal gray as well as the superior colliculus are important for the strike period. On the basis of the reviewed data, this three-stage model should be extended (see also the insightful account of behavior organization put forth by Craig 1918) to include a post-strike phase characterized by the emotion of relief, behaviorally expressed as startle attenuation and mediated by the nucleus accumbens. The positive valence of this phase is biologically reasonable because it can reinforce those behaviors that helped to escape or otherwise master and survive the threat (Smith and Buchanan 1954; Ilango et al. 2012) and the learning of the cues associated with its disappearance: Subsequently, learned approach behavior to such cues would decrease the probability of encountering the threat again. Such an extension of the threat-imminence model should provide an integrated, conceptually, and biologically meaningful framework for both punishment- and relief-learning in rats and humans. Furthermore, it should prompt Drosophila researchers to characterize the defensive behaviors of flies toward threats as well as toward shockpredicting stimuli in more detail than has been customary to date (for a pioneering analysis, see Chabaud et al. 2010). This should reveal whether invertebrate defensive behavior follows the same general principles. Indeed, using terminology that may appear old fashioned today, the early neuroethologists around Craig, von Holst, Tinbergen, von Frisch, and Lorenz were applying a hierarchical and sequential framework of behavior organization featuring the steps of (1) need-related, spatially undirected search behavior and attention, (2) spatially directed orientation behavior and attention, and (3) eventual action and the embodiment of consequences (Craig 1918; Lorenz and Tinbergen 1938; Bullock and Horridge 1965; Lorenz 1973).

\section{Perspectives for applied psychology}

The reviewed data suggest that considering relief-learning can also help us to understand some features of odd and/or pathological behavior. For example, "having survived" a roller-coaster ride or extreme sports may support relief-learning by activating reward circuitry, reinforce these activities, give the situation an implicit positive valence, and thus explain an otherwise irrational tendency to perform such dangerous activities again (Solomon and Corbit 1974). Likewise, self-cutting and related nonsuicidal selfinjury may be operant behaviors carried out in order to access relief (Franklin et al. 2013a,b). Moreover, the relief experienced by a hostage following acute repeated death threats may help explain the development of positive feelings toward the hostage taker ("Stockholm syndrome"). Relief-learning may also contribute to the attraction of anxiety patients to cues associated with fear offset such as medication, or the hospital or therapy environment, and may explain why items not plausibly causally related to but temporally linked with fear offset can become fear-fighting talismans. Similar scenarios may apply regarding the offset of traumatic events or of panic attacks and the safety-seeking behavior that may emerge. Further, hypervigilance to signals of upcoming threat (Bishop 2007) together with a deficit in the perception of (or deficits in learning about) offset signals may turn a bad experience into an unbearable one (see also Box 2), and thus contribute to the susceptibility for post-traumatic stress or panic disorder (Mineka and Oehlberg 2008; Jovanovic et al. 2012). For example, patients suffering from post-traumatic stress disorder not only express enhanced fear-learning but also a reduced response to safety signals (Jovanovic et al. 2012). Furthermore, successful safety-seeking behavior may contribute to the maintenance of anxiety disorders such as panic disorders or agoraphobia (Lohr et al. 2007). We note that in flies at least (and preliminary data suggest that it is similar in rats) memories after relief-learning are temporally more stable than memories after punishment-learning relatively early (up to $2 \mathrm{~h}$ ) after conditioning (Yarali et al. 2008; Diegelmann et al. $2013 b$ ). If this were the case in humans, too, deficiencies in relief-learning might render subjects more susceptible in particular to repeated adverse experiences occurring in relatively quick succession, such that the net effect of a sequence of grave experiences is turned into an unbearable, traumatic one.

To summarize, relief-learning can be observed in species as distantly related as flies, rats, and man. This draws attention to the mnemonic processes related to the offset of reinforcers; indeed, these processes may prove to be no less universally conserved than those related to reinforcement onset (Rescorla 1988) and thus lend themselves to translational research. Specifically, we believe that the full range of the behavioral and psychological consequences of painful and/or traumatic experiences cannot be appreciated without taking relief-learning into account. As we argue, relief-learning should be considered in particular when trying to understand the development and maintenance of both adaptive avoidance behavior and of pathological conditions such as exaggerated risk-taking, self-injury, excessive safetyseeking, post-traumatic stress disorder as well as panic disorders. In all these cases, attention in particular seems warranted as to whether or not modifications of these behaviors or the considered therapy are differentially effective for fear- and relief-memories. To this end, basic and translational research into the cellular, molecular, and genetic bases for punishment- and relief-learning is both useful and fascinating.

\section{Acknowledgments}

The following bodies funded and/or fund the research programs of our groups: the Leibniz Institut für Neurobiologie (LIN) Magdeburg; the Wissenschaftsgemeinschaft Gottfried Wilhelm Leibniz (WGL); the Center for Behavioral Brain Science, Magdeburg (B.G., A.Y., M.F.); the Max Planck Gesellschaft (A.Y., C.T.W.), the Universities of Würzburg (B.G., P.P.), Leipzig (B.G.), and Magdeburg (B.G., M.F.); the Boehringer Ingelheim Funds (A.Y.); the Human Frontiers Science Program (A.Y.); and the Deutsche Forschungsgemeinschaft (B.G., Heisenberg Programm, CRC TR 58-A6, CRC 779-B11; A.Y., research grant, YA 272/2-1; 
S.D., CRC 779-B11; P.P., CRC TR 58-B1; M.F., CRC 779-B13). We especially thank E. Münch, Würzburg, for support to A.Y. at a critical moment in her career, and to R. Glasgow, Zaragoza, for editing and comments.

In addition to the privilege of working with the colleagues and staff of our research groups, we have benefited at times from controversial discussions with and comments on this manuscript by Y. Aso, Ashburn; E. Buchner, Würzburg; J. Classen, Leipzig; A. Fallgatter, Tübingen; M. Heisenberg, Würzburg; F. Hellstern, Hesselbach; R. Menzel, Berlin; P. Tobler, Zürich; M. Wöhr, Marburg; and T. Zars, Columbia, Missouri.

This article is dedicated to the memory of the late Martin Hammer on the occasion of the 20th anniversary of his discovery in 1993 that the single, identified, unpaired octopaminergic Vum $_{\mathrm{mx} 1}$ neuron is sufficient for appetitive reinforcement in the honeybee.

\section{References}

Abrams TW, Yovell Y, Onyike CU, Cohen JE, Jarrard HE. 1998. Analysis of sequence-dependent interactions between transient calcium and transmitter stimuli in activating adenylyl cyclase in Aplysia: possible contribution to CS-US sequence requirement during conditioning. Learn Mem 4: 496-509.

Adamec RE, Shallow T. 1993. Lasting effects on rodent anxiety of a single exposure to a cat. Physiol Behav 54: 101-109.

Amano T, Unal CT, Pare D. 2010. Synaptic correlates of fear extinction in the amygdala. Nat Neurosci 13: 489-494.

Amrhein C, Mühlberger A, Pauli P, Wiedemann G. 2004. Modulation of event-related brain potentials during affective picture processing: a complement to startle reflex and skin conductance response? Int J Psychophysiol 54: 231-240.

Andreatta M, Mühlberger A, Yarali A, Gerber B, Pauli P. 2010. A rift between implicit and explicit conditioned valence in human pain relief-learning. Proc Biol Sci 277: 2411-2416.

Andreatta M, Fendt M, Mühlberger A, Wieser MJ, Imobersteg S, Yarali A Gerber B, Pauli P. 2012. Onset and offset of aversive events establish distinct memories requiring fear and reward networks. Learn Mem 19: 518-526.

Andreatta M, Mühlberger A, Glotzbach-Schoon E, Pauli P. 2013. Pain predictability reverses valence ratings of a relief-associated stimulus. Front Syst Neurosci 7: 53.

Angrilli A, Mauri A, Palomba D, Flor H, Birbaumer N, Sartori G, di Paola F. 1996. Startle reflex and emotion modulation impairment after a right amygdala lesion. Brain 119: 1991-2000.

Aso Y, Siwanowicz I, Bracker L, Ito K, Kitamoto T, Tanimoto H. 2010. Specific dopaminergic neurons for the formation of labile aversive memory. Curr Biol 20: $1445-1451$.

Aso Y, Herb A, Ogueta M, Siwanowicz I, Templier T, Friedrich AB, Ito K, Scholz H, Tanimoto H. 2012. Three dopamine pathways induce aversive odor memories with different stability. PLoS Genet 8: e1002768.

Barth J, Dipt S, Pech U, Hermann M, Riemensperger T, Fiala A. 2014 Differential associative training enhances olfactory acuity in Drosophila melanogaster. J Neurosci 34: 1819-1837.

Baxter DA, Byrne JH. 2006. Feeding behavior of Aplysia: a model system for comparing cellular mechanisms of classical and operant conditioning. Learn Mem 13: 669-680.

Bayer HM, Lau B, Glimcher PW. 2007. Statistics of midbrain dopamine neuron spike trains in the awake primate. J Neurophysiol 98: 1428-1439.

Becerra L, Borsook D. 2008. Signal valence in the nucleus accumbens to pain onset and offset. Eur J Pain 12: 866-869.

Bechara A, Tranel D, Damasio H, Adolphs R, Rockland C, Damasio AR. 1995. Double dissociation of conditioning and declarative knowledge relative to the amygdala and hippocampus in humans. Science 269: $1115-1118$.

Bechara A, Damasio H, Damasio AR, Lee GP. 1999. Different contributions of the human amygdala and ventromedial prefrontal cortex to decision-making. J Neurosci 19: 5473-5481.

Benjamin PR, Kemenes G, Kemenes I. 2008. Non-synaptic neuronal mechanisms of learning and memory in gastropod molluscs. Front Biosci 13: 4051-4057.

Benning SD, Patrick CJ, Lang AR. 2004. Emotional modulation of the post-auricular reflex. Psychophysiology 41: 426-432.

Berg K, Balaban MT. 1999. Startle elicitation: stimulus parameters, recording techniques, and quantification. In Startle modification: implications for neuroscience, cognitive science, and clinical science (ed. Dawson ME, Schell AM, Bohmelt AH), pp. 21-50. University Press, Cambridge, UK.

Berridge KC, Robinson TE. 1998. What is the role of dopamine in reward: hedonic impact, reward learning, or incentive salience? Brain Res Brain Res Rev 28: 309-369.

Berry JA, Cervantes-Sandoval I, Nicholas EP, Davis RL. 2012. Dopamine is required for learning and forgetting in Drosophila. Neuron 74: $530-542$.

Bi GQ, Poo MM. 2001. Synaptic modification by correlated activity: Hebb's postulate revisited. Annu Rev Neurosci 24: 139-166.

Bishop SJ. 2007. Neurocognitive mechanisms of anxiety: an integrative account. Trends Cogn Sci 11: 307-316.

Blanchard RJ, Blanchard DC. 1989. Antipredator defensive behaviors in a visible burrow system. J Comp Psychol 103: 70-82.

Blum AL, Li W, Cressy M, Dubnau J. 2009. Short- and long-term memory in Drosophila require cAMP signaling in distinct neuron types. Curr Biol 19: $1341-1350$.

Blumenthal TD, Cuthbert BN, Filion DL, Hackley S, Lipp OV. 2005. Committee report: guidelines for human startle eyeblink electromyographic studies. Psychophysiology 42: 1-15.

Brischoux F, Chakraborty S, Brierley DI, Ungless MA. 2009. Phasic excitation of dopamine neurons in ventral VTA by noxious stimuli. Proc Natl Acad Sci 106: 4894-4899.

Bromberg-Martin ES, Matsumoto M, Hokosaka O. 2010. Dopamine in motivational control: rewarding, aversive, and alerting. Neuron 68: $815-834$

Brown JS, Kalish HI, Farber IE. 1951. Conditioned fear as revealed by magnitude of startle response to an auditory stimulus. J Exp Psychol 41: $317-328$.

Büchel C, Morris J, Dolan RJ, Friston KJ. 1998. Brain systems mediating aversive conditioning: an event-related fRMI study. Neuron 20: 947-957.

Bullock TH, Horridge GA. 1965. Structure and function of the nervous system of invertebrates. WH Freeman and Company, San Francisco, London, UK.

Burke CJ, Huetteroth W, Owald D, Perisse E, Krashes MJ, Das G, Gohl D, Silies M, Certel S, Waddell S. 2012. Layered reward signalling through octopamine and dopamine in Drosophila. Nature 492: $433-437$.

Campbell RA, Honegger KS, Qin H, Li W, Demir E, Turner GC. 2013. Imaging a population code for odor identity in the Drosophila mushroom body. J Neurosci 33: 10568-10581.

Caporale N, Dan Y. 2008. Spike timing-dependent plasticity: a Hebbian learning rule. Annu Rev Neurosci 31: 25-46.

Cardinal RN, Everitt BJ. 2004. Neural and psychological mechanisms underlying appetitive learning: links to drug addiction. Curr Opin Neurobiol 14: $156-162$.

Cassenaer S, Laurent G. 2007. Hebbian STDP in mushroom bodies facilitates the synchronous flow of olfactory information in locusts. Nature 448: 709-713.

Cassenaer S, Laurent G. 2012. Conditional modulation of spike-timingdependent plasticity for olfactory learning. Nature 482: 47-52.

Chabaud MA, Preat T, Kaiser L. 2010. Behavioral characterization of individual olfactory memory retrieval in Drosophila melanogaster. Front Behav Neurosci 4: 192 .

Chang RC, Blaisdell AP, Miller RR. 2003. Backward conditioning: mediation by the context. J Exp Psychol Anim Behav Process 29: $171-183$.

Christian KM, Thompson RF. 2003. Neural substrates of eyeblink conditioning: acquisition and retention. Learn Mem 10: 427-455.

Christianson JP, Fernando ABP, Kazama AM, Jovanovic T, Ostroff LE, Sangha S. 2012. Inhibition of fear by learned safety signals: a minisymposium review. J Neurosci 32: 14118-14124.

Claridge-Chang A, Roorda RD, Vrontou E, Sjulson L, Li H, Hirsh J, Miesenbock G. 2009. Writing memories with light-addressable reinforcement circuitry. Cell 139: 405-415.

Cohen JY, Haesler S, Vong L, Lowell BB, Uchida N. 2012. Neuron-type-specific signals for reward and punishment in the ventral tegmental area. Nature 482: 85-88.

Colomb J, Kaiser L, Chabaud MA, Preat T. 2009. Parametric and genetic analysis of Drosophila appetitive long-term memory and sugar motivation. Genes Brain Behav 8: 407-415.

Conzelmann A, Mucha R, Jacob CP, Weyers P, Romanos J, Gerdes ABM, Baehne CG, Boreatti-Hümmer A, Heine M, Alpers GW, et al. 2009. Abnormal affective responsiveness in attention-deficit/hyperactivity disorder: subtype differences. Biol Psychiatry 65: 578-585.

Cousens GA, Skrobacz CG, Blumenthal A. 2011. Nucleus accumbens carbachol disrupts olfactory and contextual fear-potentiated startle and attenuates baseline startle reactivity. Behav Brain Res 216: 673-680.

Cox SM, Andrade A, Johnsrude IS. 2005. Learning to like: a role for human orbitofrontal cortex in conditioned reward. J Neurosci 25: $2733-2740$. 
Craig W. 1918. Appetites and aversions as constituents of instincts. Biol Bull 34: $91-107$.

Craig AD. 2009. How do you feel-now? The anterior insula and human awareness. Nat Rev Neurosci 10: 59-70.

Davis RL. 2005. Olfactory memory formation in Drosophila: from molecular to systems neuroscience. Annu Rev Neurosci 28: 275-302.

Davis M. 2006. Neural systems involved in fear and anxiety measured with fear-potentiated startle. Am Psychol 61: 741-756.

Davis M, Falls WA, Campeau S, Kim M. 1993. Fear-potentiated startle: a neural and pharmacological analysis. Behav Brain Res 58: 175-198.

Davis M, Antoniadis EA, Amaral DG, Winslow JT. 2008. Acoustic startle reflex in rhesus monkeys: a review. Rev Neurosci 19: 171-185.

Davis M, Walker DL, Miles L, Grillon C. 2009. Phasic vs sustained fear in rats and humans: role of the extended amygdala in fear vs anxiety. Neuropsychopharmacology 35: 105-135.

Dawson ME, Schell A, Böhmelt AH. 1999. Startle modification: introduction and overview. In Startle modification: implications for neuroscience, cognitive science, and clinical science (ed. Dawson ME, Schell AM, Bohmelt AH), pp. 6-18. University Press, Cambridge, UK.

Delgado MR, Olsson A, Phelps EA. 2006. Extending animal models of fear conditioning to humans. Biol Psychol 73: 39-48.

Demerec M, Kaufmann BP. 1973. Drosophila guide. Carnegie Institution, Washington, DC.

Diegelmann S, Zars M, Zars T. 2006. Genetic dissociation of acquisition and memory strength in the heat-box spatial learning paradigm in Drosophila. Learn Mem 13: 72-83.

Diegelmann S, Klagges B, Michels B, Schleyer M, Gerber B. 2013a. Maggot learning and Synapsin function. J Exp Biol 216: 939-951.

Diegelmann S, Preuschoff S, Appel M, Niewalda T, Gerber B, Yarali A. 2013b. Memory decay and susceptibility to amnesia dissociate punishment- from relief-learning. Biol Lett 9: 20121171.

Drew PJ, Abbott LF. 2006. Extending the effects of spike-timing-dependent plasticity to behavioral timescales. Proc Natl Acad Sci 103: 8876-8881.

Dubnau J, Tully T. 2001. Functional anatomy: from molecule to memory. Curr Biol 11: R240-R243.

Dubnau J, Grady L, Kitamoto T, Tully T. 2001. Disruption of neurotransmission in Drosophila mushroom body blocks retrieval but not acquisition of memory. Nature 411: 476-480.

Ehrlich I, Humeau Y, Grenier F, Ciocchi S, Herry C, Luthi A. 2009. Amygdala inhibitory circuits and the control of fear memory. Neuron 62: $757-771$.

Elliott R, Friston KJ, Dolan RJ. 2000. Dissociable neural responses in human reward systems. J Neurosci 20: 6159-6165.

Eschbach C, Cano C, Haberkern H, Schraut K, Guan C, Triphan T, Gerber B. 2011. Associative learning between odorants and mechanosensory punishment in larval Drosophila. J Exp Biol 214: 3897-3905.

Evans JM, Day JP, Cabrero P, Dow JA, Davies SA. 2008. A new role for a classical gene: white transports cyclic GMP. J Exp Biol 211: 890-899.

Fanselow MS. 1994. Neural organization of the defensive behavior system responsible for fear. Psychon Bull Rev 1: 429-438.

Fanselow MS, Poulos AM. 2005. The neuroscience of mammalian associative learning. Annu Rev Psychol 56: 207-234.

Felsenberg J, Plath JA, Lorang S, Morgenstern L, Eisenhardt D. 2013. Shortand long-term memories formed upon backward conditioning in honeybees (Apis mellifera). Learn Mem 21: 37-45.

Fendt M, Fanselow MS. 1999. The neuroanatomical and neurochemical basis of conditioned fear. Neurosci Biobehav Rev 23: 743-760.

Fendt M, Endres T, Apfelbach R. 2003. Temporary inactivation of the bed nucleus of the stria terminalis but not of the amygdala blocks freezing induced by trimethylthiazoline, a component of fox feces. J Neurosci 23: $23-28$.

Fiorillo CD. 2013. Two dimensions of value: dopamine neurons represent reward but not aversiveness. Science 341: 546-549.

Fiorillo CD, Song MR, Yun SR. 2013a. Multiphasic temporal dynamics in responses of midbrain dopamine neurons to appetitive and aversive stimuli. J Neurosci 33: 4710-4725.

Fiorillo CD, Yun SR, Song MR. 2013b. Diversity and homogeneity in responses of midbrain dopamine neurons. J Neurosci 33: 4693-4709.

Franklin JC, Lee KM, Hanna EK, Prinstein MJ. 2013a. Feeling worse to feel better: pain-offset relief simultaneously stimulates positive affect and reduces negative affect. Psychol Sci 24: 521-529.

Franklin JC, Puzia ME, Lee KM, Lee GE, Hanna EK, Spring VL, Prinstein MJ. 2013b. The nature of pain offset relief in nonsuicidal self-injury: a laboratory study. Clin Psychol Sci 1: 110.

Fujiwara J, Tobler PN, Taira M, Iijima T, Tsutsui K-I. 2009. A parametric relief signal in human ventrolateral prefrontal cortex. Neuroimage 44: $1163-1170$.

Geier A, Mucha RF, Pauli P. 2000. Appetitive nature of drug cues confirmed with physiological measures in a model using pictures of smoking. Psychopharmacology 150: 283-291.

Gerber B, Tanimoto H, Heisenberg M. 2004. An engram found? Evaluating the evidence from fruit flies. Curr Opin Neurobiol 14: 737-744.
Gervasi N, Tchenio P, Preat T. 2010. PKA dynamics in a Drosophila learning center: coincidence detection by rutabaga adenylyl cyclase and spatial regulation by dunce phosphodiesterase. Neuron 65: 516-529.

Giurfa M, Sandoz JC. 2012. Invertebrate learning and memory: fifty years of olfactory conditioning of the proboscis extension response in honeybees. Learn Mem 19: 54-66.

Glotzbach-Schoon E, Tadda R, Andreatta M, Tröger C, Ewald H, Grillon C, Pauli P, Mühlberger A. 2013. Enhanced discrimination between threatening and safe contexts in high-anxious individuals. Biol Psychol 93: $159-166$

Gottfried JA, O'Doherty J, Dolan RJ. 2002. Appetitive and aversive olfactory learning in humans studied using event-related functional magnetic resonance imaging. J Neurosci 22: 10829-10837.

Grillon C. 2002. Startle reactivity and anxiety disorders: aversive conditioning, context, and neurobiology. Biol Psychiatry 52: 958-975.

Grillon C, Baas J. 2003. A review of the modulation of the startle reflex by affective states and its application in psychiatry. Clin Neurophysiol 114: $1557-1579$

Hamm AO, Schupp HT, Weike AI. 2003a. Motivational organization of emotions: autonomic changes, cortical responses, and reflex modulation. In Handbook of affective sciences (ed. Davidson RJ, Scherer KR, Hill Goldsmith H), pp. 187-211. Oxford University Press, Oxford, UK.

Hamm AO, Weike AI, Schupp HT, Treig T, Dressel A, Kessler C. 2003b. Affective blindsight: intact fear conditioning to a visual cue in a cortically blind patient. Brain 126: 267-275.

Hammer M. 1993. An identified neuron mediates the unconditioned stimulus in associative olfactory learning in honeybees. Nature 366: 59-63.

Han KA, Millar NS, Grotewiel MS, Davis RL. 1996. DAMB, a novel dopamine receptor expressed specifically in Drosophila mushroom bodies. Neuron 16: $1127-1135$.

Heinbockel T, Pape HC. 2000. Input-specific long-term depression in the lateral amygdala evoked by theta frequency stimulation. J Neurosci 20: RC68.

Heisenberg M. 2003. Mushroom body memoir: from maps to models. Nat Rev Neurosci 4: $266-275$.

Heisenberg M, Gerber B. 2008. Learning and memory in Drosophila. In Learning theory and behavior (ed. Menzel R), pp. 549-559. Elsevier, Oxford, UK.

Hellstern F, Malaka R, Hammer M. 1998. Backward inhibitory learning in honeybees: a behavioral analysis of reinforcement processing. Learn Mem 4: $429-444$

Helmstetter FJ, Bellgowan PS. 1994. Effects of muscimol applied to the basolateral amygdala on acquisition and expression of contextual fear conditioning in rats. Behav Neurosci 108: 1005-1009.

Hermann C, Ziegler S, Birbaumer N, Flor H. 2000. Pavlovian aversive and appetitive odor conditioning in humans: subjective, peripheral and electrocortical changes. Exp Brain Res 132: 203-215.

Heth CD. 1976. Simultaneous and backward fear conditioning as a function of number of CS-UCS pairings. J Exp Psychol Anim Behav Process 2: $117-129$.

Heth CD, Rescorla RA. 1973. Simultaneous and backward fear conditioning in the rat. J Comp Physiol Psychol 82: 434.

Hitchcock J, Davis M. 1986. Lesions of the amygdala, but not of the cerebellum or red nucleus, block conditioned fear as measured with the potentiated startle paradigm. Behav Neurosci 100: 11-22.

Hofmann W, De Houwer J, Perugini M, Baeyens F, Crombez G. 2010. Evaluative conditioning in humans: a meta-analysis. Psychol Bull 136: $390-421$.

Howells AJ, Summers KM, Ryall RL. 1977. Developmental patterns of 3-hydroxykynurenine accumulation in white and various other eye color mutants of Drosophila melanogaster. Biochem Genet 15: 1049-1059.

Hunt PS, Richardson R, Campbell BA. 1994. Delayed development of fear-potentiated startle in rats. Behav Neurosci 108: 69-80.

Ikemoto S, Panksepp J. 1996. Dissociations between appetitive and consummatory responses by pharmacological manipulations of reward-relevant brain regions. Behav Neurosci 110: 331-345.

Ikemoto S, Panksepp J. 1999. The role of nucleus accumbens dopamine in motivated behavior: a unifying interpretation with special reference to reward-seeking. Brain Res Brain Res Rev 31: 6-41.

Ilango A, Shumake J, Wetzel W, Scheich H, Ohl FW. 2012. The role of dopamine in the context of aversive stimuli with particular reference to acoustically signaled avoidance learning. Front Neurosci 6: 132 .

Isabel G, Pascual A, Preat T. 2004. Exclusive consolidated memory phases in Drosophila. Science 304: 1024-1027.

Ito I, Ong RC, Raman B, Stopfer M. 2008. Sparse odor representation and olfactory learning. Nat Neurosci 11: 1177-1184.

Josselyn SA, Falls WA, Gewirtz JC, Pistell P, Davis M. 2005. The nucleus accumbens is not critically involved in mediating the effects of a safety signal on behavior. Neuropsychopharmacology 30: 17-26. 
Jovanovic T, Kazama A, Bachevalier J, Davis M. 2012. Impaired safety signal learning may be a biomarker of PTSD. Neuropharmacology 62: 695-704.

Kahnt T, Park SQ, Burke CJ, Tobler PN. 2012. How glitter relates to gold: similarity-dependent reward prediction errors in the human striatum. J Neurosci 32: 16521-16529.

Kahsai L, Zars T. 2011. Learning and memory in Drosophila: behavior, genetics, and neural systems. Int Rev Neurobiol 99: 139-167.

Keene AC, Waddell S. 2007. Drosophila olfactory memory: single genes to complex neural circuits. Nat Rev Neurosci 8: 341-354

Keene AC, Krashes MJ, Leung B, Bernard JA, Waddell S. 2006. Drosophila dorsal paired medial neurons provide a general mechanism for memory consolidation. Curr Biol 16: 1524-1530.

Kim YC, Lee HG, Seong CS, Han KA. 2003. Expression of a D1 dopamine receptor dDA1/DmDOP1 in the central nervous system of Drosophila melanogaster. Gene Expr Patterns 3: 237-245.

Kim H, Shimojo S, O’Doherty JP. 2006. Is avoiding an aversive outcome rewarding? Neural substrates of avoidance learning in the human brain. PLoS Biol 4: e233.

Kim YC, Lee HG, Han KA. 2007. D1 dopamine receptor dDA1 is required in the mushroom body neurons for aversive and appetitive learning in Drosophila. J Neurosci 27: 7640-7647.

Kirsch P, Schienle A, Stark R, Sammer G, Blecker C, Walter B, Ott U, Burkart J, Vaitl D. 2003. Anticipation of reward in a nonaversive differential conditioning paradigm and the brain reward system: an event-related fMRI study. Neuroimage 20: 1086-1095.

Knapek S, Gerber B, Tanimoto H. 2010. Synapsin is selectively required for anesthesia-sensitive memory. Learn Mem 17: 76-79.

Knutson B, Adams CM, Fong GW, Hommer D. 2001. Anticipation of increasing monetary reward selectively recruits nucleus accumbens. J Neurosci 21: RC159.

Koch M. 1999. The neurobiology of startle. Prog Neurobiol 59: 107-128.

Koch M, Schmid A, Schnitzler HU. 1996. Pleasure-attenuation of startle is disrupted by lesions of the nucleus accumbens. Neuroreport 7: $1442-1446$.

Kong E, Monje FJ, Hirsch J, Pollak DD. 2013. Learning not to fear: neural correlates of learned safety. Neuropsychopharmacology 39: 515-527.

Konorski J. 1948. Conditioned reflexes and neuron organisation. Cambridge University Press, Cambridge, UK.

Koshimura K, Murakami Y, Tanaka J, Kato Y. 2000. The role of 6Rtetrahydrobiopterin in the nervous system. Prog Neurobiol 61: 415-438.

Krashes MJ, Waddell S. 2008. Rapid consolidation to a radish and protein synthesis-dependent long-term memory after single-session appetitive olfactory conditioning in Drosophila. J Neurosci 28: 3103-3113.

Krashes MJ, DasGupta S, Vreede A, White B, Armstrong JD, Waddell S. 2009. A neural circuit mechanism integrating motivational state with memory expression in Drosophila. Cell 139: 416-427.

LaBar KS, Gatenby JC, Gore JC, LeDoux JE, Phelps EA. 1998. Human amygdala activation during conditioned fear acquisition and extinction: a mixed-trial fRMI study. Neuron 20: 937-945.

Lammel S, Lim BK, Ran C, Huang KW, Betley MJ, Tye KM, Deisseroth K, Malenka RC. 2012. Input-specific control of reward and aversion in the ventral tegmental area. Nature 491: 212-217.

Landis C, Hunt WA. 1939. The startle pattern. Farrar and Rinehart, New York.

Lang PJ, Bradley MM, Cuthbert BN. 1990. Emotion, attention, and the startle reflex. Psychol Rev 97: 377-395.

Lang PJ, Davis M, Öhman A. 2000. Fear and anxiety: animal models and human cognitive psychophysiology. J Affect Dis 61: 137-159.

Laurent G, Stopfer M, Friedrich RW, Rabinovich MI, Volkovskii A, Abarbanel HD. 2001. Odor encoding as an active, dynamical process: experiments, computation, and theory. Annu Rev Neurosci 24: 263-297.

Lechner HA, Byrne JH. 1998. New perspectives on classical conditioning: a synthesis of Hebbian and non-Hebbian mechanisms. Neuron 20 $355-358$.

LeDoux JE. 2000. Emotion circuits in the brain. Annu Rev Neurosci 23: $155-184$.

Leknes S, Lee M, Berna C, Andersson J, Tracey I. 2011. Relief as a reward: hedonic and neural responses to safety from pain. PLoS One 6: e17870.

Leone S. 1966. The good, the bad, and the ugly. United Artists.

Levita L, Hoskin P, Champi S. 2012. Avoidance of harm and anxiety: a role for the nucleus accumbens. Neuroimage 62: 189-198.

Lipp OV, Sheridan J, Siddle DA. 1994. Human blink startle during aversive and nonaversive Pavlovian conditioning. J Exp Psychol Anim Behav Process 20: 380-389.

Liu C, Placais PY, Yamagata N, Pfeiffer BD, Aso Y, Friedrich AB, Siwanowicz I, Rubin GM, Preat T, Tanimoto H. 2012. A subset of dopamine neurons signals reward for odour memory in Drosophila. Nature 488: $512-516$.

Lohr JM, Olatunji BO, Sawchuk CN. 2007. A functional analysis of danger and safety signals in anxiety disorders. Clin Psychol Rev 27: 114-126.

Lorenz K. 1973. Autobiography. In Les Prix Nobel (ed. Odelberg W), pp. 176-183. Nobel Foundation, Stockholm.
Lorenz K, Tinbergen N. 1938. Taxis und Instinkthandlung in der Eirollbewegung der Graugans. Z Tierpsychol 2: 1-29.

Löw A, Lang PJ, Smith JC, Bradley MM. 2008. Both predator and prey: emotional arousal in threat and reward. Psychol Sci 19: 865-873.

Maier SF, Rapaport P, Wheatley KL. 1976. Conditioned inhibition and the UCS-CS interval. Anim Learn Behav 4: 217-220.

Malaka R. 1999. Models of classical conditioning. Bull Math Biol 61: 33-83.

Mao Z, Davis RL. 2009. Eight different types of dopaminergic neurons innervate the Drosophila mushroom body neuropil: anatomical and physiological heterogeneity. Front Neural Circuits 3: 5.

Maren S. 2001. Neurobiology of Pavlovian fear conditioning. Annu Rev Neurosci 24: 897-931.

Maren S, Aharonov G, Stote DL, Fanselow MS. 1996. N-Methyl-D-aspartate receptors in the basolateral amygdala are required for both acquisition and expression of conditional fear in rats. Behav Neurosci 110: $1365-1374$.

Markram H, Gerstner W, Sjöström PJ. 2011. A history of spike-timing-dependent plasticity. Front Synaptic Neurosci 3: 4

Martin JH. 1991. Autoradiographic estimation of the extent of reversible inactivation produced by microinjection of lidocaine and muscimol in the rat. Neurosci Lett 127: 160-164.

McGuire SE, Le PT, Davis RL. 2001. The role of Drosophila mushroom body signaling in olfactory memory. Science 293: 1330-1333.

McKernan MG, Shinnick-Gallagher P. 1997. Fear conditioning induces a lasting potentiation of synaptic currents in vitro. Nature 390: 607-611.

Menzel R. 2001. Searching for the memory trace in a mini-brain, the honeybee. Learn Mem 8: 53-62.

Menzel R. 2012. The honeybee as a model for understanding the basis of cognition. Nat Rev Neurosci 13: 758-768.

Menzel R. 2013. In search of the engram in the honeybee brain. In Invertebrate learning and memory (ed. Menzel R, Benjamin PR), pp. 397-415. Academic Press, London, UK.

Michels B, Chen YC, Saumweber T, Mishra D, Tanimoto H, Schmid B Engmann O, Gerber B. 2011. Cellular site and molecular mode of synapsin action in associative learning. Learn Mem 18: 332-344.

Milad MR, Quirk GJ. 2012. Fear extinction as a model for translational neuroscience: ten years of progress. Annu Rev Psychol 63: 129-151.

Mineka S, Oehlberg K. 2008. The relevance of recent developments in classical conditioning to understanding the etiology and maintenance of anxiety disorders. Acta Psychol (Amst) 127: 567-580.

Miserendino MJ, Sananes CB, Melia KR, Davis M. 1990. Blocking of acquisition but not expression of conditioned fear-potentiated startle by NMDA antagonists in the amygdala. Nature 345: 716-718.

Morris JS, Ohman A, Dolan RJ. 1998. Conscious and unconscious emotional learning in the human amygdala. Nature 393: 467-470.

Moscovitch A, LoLordo VM. 1968. Role of safety in the Pavlovian backward fear conditioning procedure. J Comp Physiol Psychol 66: $673-678$

Müller M, Fendt M. 2006. Temporary inactivation of the medial and basolateral amygdala differentially affects TMT-induced fear behavior in rats. Behav Brain Res 167: 57-62.

Muller J, Corodimas KP, Fridel Z, LeDoux JE. 1997. Functional inactivation of the lateral and basal nuclei of the amygdala by muscimol infusion prevents fear conditioning to an explicit conditioned stimulus and to contextual stimuli. Behav Neurosci 111: $683-691$.

Murthy M, Fiete I, Laurent G. 2008. Testing odor response stereotypy in the Drosophila mushroom body. Neuron 59: 1009-1023.

Nakamura M, Ueno S, Sano A, Tanabe H. 1999. Polymorphisms of the human homologue of the Drosophila white gene are associated with mood and panic disorders. Mol Psychiatry 4: 155-162.

Navratilova E, Xie JY, Okun A, Qu CL, Eyde N, Ci S, Ossipov MH, King T, Fields HL, Porreca F. 2012. Pain relief produces negative reinforcement through activation of mesolimbic reward-valuation circuitry. Proc Nat Acad Sci 109: 20709-20713.

Nemeroff CB, Bremner JD, Foa EB, Mayberg HS, North CS, Stein MB. 2006. Posttraumatic stress disorder: a state-of-the-science review. I Psychiatr Res 40: $1-21$.

Niewalda T, Voller T, Eschbach C, Ehmer J, Chou WC, Timme M, Fiala A, Gerber B. 2011. A combined perceptual, physico-chemical, and imaging approach to "odour-distances" suggests a categorizing function of the Drosophila antennal lobe. PLoS One 6: e24300.

Norrholm SD, Anderson KM, Olin IW, Jovanovic T, Kwon C, Warren VT, McCarthy A, Bosshardt L, Sabree J, Duncan EJ, et al. 2011. Versatility of fear-potentiated startle paradigms for assessing human conditioned fear extinction and return of fear. Front Behav Neurosci 5: 77.

O’Doherty JP, Deichmann R, Critchley HD, Dolan RJ. 2002. Neural responses during anticipation of a primary taste reward. Neuron 33: $815-826$.

O’Doherty JP, Dayan P, Friston KJ, Critchley HD, Dolan RJ. 2003. Temporal difference models and reward-related learning in the human brain. Neuron 38: 329-337. 
O'Hare K, Murphy C, Levis R, Rubin GM. 1984. DNA sequence of the white locus of Drosophila melanogaster. J Mol Biol 180: 437-455.

Öhman A. 2008. Fear and anxiety: overlaps and dissociations. In Handbook of emotions, 3rd ed. (ed. Lewis M, Haviland-Jones JM), pp. 709-729. Guilford, New York.

Öhman A, Mineka S. 2001. Fears, phobias, and preparedness: toward an evolved module of fear and fear learning. Psychol Rev 108: 483-522.

Pape HC, Pare D. 2010. Plastic synaptic networks of the amygdala for the acquisition, expression, and extinction of conditioned fear. Physiol Rev 90: $419-463$

Pech U, Pooryasin A, Birman S, Fiala A. 2013. Localization of the contacts between Kenyon cells and aminergic neurons in the Drosophila melanogaster brain using splitGFP reconstitution. J Comp Neurol 521: 3992-4026.

Peele P, Ditzen M, Menzel R, Galizia CG. 2006. Appetitive odor learning does not change olfactory coding in a subpopulation of honeybee antennal lobe neurons. J Comp Physiol A 192: 1083-1103.

Pereira AG, Cruz A, Lima SQ, Moita MA. 2012. Silence resulting from the cessation of movement signals danger. Curr Biol 22: R627-R628.

Perisse E, Yin Y, Lin AC, Lin S, Huetteroth W, Waddell S. 2013. Different Kenyon cell populations drive learned approach and avoidance in Drosophila. Neuron 79: 945-956.

Placais PY, Trannoy S, Isabel G, Aso Y, Siwanowicz I, Belliart-Guerin G, Vernier P, Birman S, Tanimoto H, Preat T. 2012. Slow oscillations in two pairs of dopaminergic neurons gate long-term memory formation in Drosophila. Nat Neurosci 15: 592-599.

Plotkin HC, Oakley DA. 1975. Backward conditioning in the rabbit (Oryctolagus cuniculus). J Comp Physiol Psychol 88: 586-590.

Pollak DD, Monje FJ, Zuckerman L, Denny CA, Drew MR, Kandel ER. 2008 An animal model of a behavioral intervention for depression. Neuron 60: $149-161$

Qin H, Cressy M, Li W, Coravos JS, Izzi SA, Dubnau J. 2012. $\gamma$ neurons mediate dopaminergic input during aversive olfactory memory formation in Drosophila. Curr Biol 22: 608-614.

Quinn WG, Harris WA, Benzer S. 1974. Conditioned behavior in Drosophila melanogaster. Proc Natl Acad Sci 71: 708-712.

Rescorla RA. 1988. Behavioral studies of Pavlovian conditioning. Аnnu Rev Neurosci 11: 329-352.

Richardson R, Wang P, Campbell BA. 1995. Delayed development of conditioned heart rate responses to auditory stimuli in the rat. Dev Psychobiol 28: 221-238.

Richardson R, Paxinos G, Lee J. 2000. The ontogeny of conditioned odor potentiation of startle. Behav Neurosci 114: 1167-1173.

Riebe CJ, Pamplona FA, Kamprath K, Wotjak CT. 2012. Fear relief-toward a new conceptual frame work and what endocannabinoids gotta do with it. Neuroscience 204: 159-185.

Riemensperger T, Voller T, Stock P, Buchner E, Fiala A. 2005. Punishment prediction by dopaminergic neurons in Drosophila. Curr Biol 15: $1953-1960$.

Rogan MT, Staubli UV, LeDoux JE. 1997. Fear conditioning induces associative long-term potentiation in the amygdala. Nature 390: 604-607.

Rogan MT, Leon KS, Perez DL, Kandel ER. 2005. Distinct neural signatures for safety and danger in the amygdala and striatum of the mouse. Neuron 46: 309-320.

Rosen JB, Schulkin J. 1998. From normal fear to pathological anxiety. Psychol Rev 105: 325-350.

Sacchetti B, Ambroqi Lorenzini C, Baldi E, Tassoni G, Bucherelli C. 1999. Memorization of contextual and CS conditioned fear response (freezing) in a one-trial acquisition paradigm. Arch Ital Biol 137: 235-248.

Sadanandappa MK, Redondo BB, Michels B, Rodrigues V, Gerber B, Vijayraghavan K, Buchner E, Ramaswami M. 2013. Synapsin function in GABA-ergic interneurons is required for short-term olfactory habituation. J Neurosci 33: 16576-16585.

Sangha S, Chadick JZ, Janak PH. 2013. Safety encoding in the basal amygdala. J Neurosci 33: 3744-3751.

Saumweber T, Husse J, Gerber B. 2011. Innate attractiveness and associative learnability of odours can be dissociated in larval Drosophila. Chem Senses 36: 223-235.

Schmid A, Koch M, Schnitzler HU. 1995. Conditioned pleasure attenuates the startle response in rats. Neurobiol Learn Mem 64: 1-3.

Schneider M, Spanagel R. 2008. Appetitive odor-cue conditioning attenuates the acoustic startle response in rats. Behav Brain Res 189: $226-230$.

Schroll C, Riemensperger T, Bucher D, Ehmer J, Voller T, Erbguth K, Gerber B, Hendel T, Nagel G, Buchner E, et al. 2006. Light-induced activation of distinct modulatory neurons triggers appetitive or aversive learning in Drosophila larvae. Curr Biol 16: 1741-1747.

Schull J. 1979. A conditioned opponent theory of Pavlovian conditioning and habituation. In Psychology of learning and motivation (ed. HB Gordon), pp. 57-90. Academic Press, New York.
Schultz W. 2013. Updating dopamine reward signals. Curr Opin Neurobiol 23: $229-238$.

Schulz B, Fendt M, Richardson R, Schnitzler HU. 2004. Temporary inactivation of the perirhinal cortex by muscimol injections block acquisition and expression of fear-potentiated startle. Eur J Neurosci 19: $713-720$.

Schupp HT, Cuthbert BN, Bradley MM, Birbaumer N, Lang PJ. 1997. Probe P3 and blinks: two measures of affective startle modulation. Psychophysiology 34: 1-6.

Schwaerzel M, Monastirioti M, Scholz H, Friggi-Grelin F, Birman S, Heisenberg M. 2003. Dopamine and octopamine differentiate between aversive and appetitive olfactory memories in Drosophila. J Neurosci 23: $10495-10502$.

Schwaerzel M, Jaeckel A, Mueller U. 2007. Signaling at A-kinase anchoring proteins organizes anesthesia-sensitive memory in Drosophila. I Neurosci 27: 1229-1233.

Schwienbacher I, Fendt M, Richardson R, Schnitzler HU. 2004. Temporary inactivation of the nucleus accumbens disrupts acquisition and expression of fear-potentiated startle in rats. Brain Res 1027: 87-93.

Schwienbacher I, Fendt M, Schnitzler HU. 2005. Amphetamine injections into the nucleus accumbens affect neither acquisition/expression of conditioned fear nor baseline startle response. Exp Brain Res 160: $538-544$

Schwienbacher I, Schnitzler HU, Westbrook RF, Richardson R, Fendt M. 2006. Carbachol injections into the nucleus accumbens disrupt acquisition and expression of fear-potentiated startle and freezing in rats. Neuroscience 140: 769-778.

Sehlmeyer C, Schöning S, Zwitserlood P, Pfleiderer B, Kircher T, Arolt V, Konrad C. 2009. Human fear conditioning and extinction in neuroimaging: a systematic review. PLoS One 4: e5865.

Sejourne J, Placais PY, Aso Y, Siwanowicz I, Trannoy S, Thoma V, Tedjakumala SR, Rubin GM, Tchenio P, Ito K, et al. 2011. Mushroom body efferent neurons responsible for aversive olfactory memory retrieval in Drosophila. Nat Neurosci 14: 903-910.

Selcho M, Pauls D, Han KA, Stocker RF, Thum AS. 2009. The role of dopamine in Drosophila larval classical olfactory conditioning. PLoS One 4: e5897.

Seymour B, O'Doherty JP, Koltzenburg M, Wiech K, Frackowiak R, Friston K, Dolan R. 2005. Opponent appetitive-aversive neural processes underlie predictive learning of pain relief. Nature 8: $1234-1240$

Siegel S, Domjan M. 1974. Inhibitory effect of backward conditioning as a function of number of backward pairings. Bull Psychon Soc 4: $122-124$

Siegmund A, Wotjak CT. 2006. Toward an animal model of posttraumatic stress disorder. Ann N Y Acad Sci 1071: 324-334.

Siegmund A, Wotjak CT. 2007. A mouse model of posttraumatic stress disorder that distinguishes between conditioned and sensitised fear. J Psychiatr Res 41: 848-860.

Sitaraman D, Zars M, Laferriere H, Chen YC, Sable-Smith A, Kitamoto T, Rottinghaus GE, Zars T. 2008. Serotonin is necessary for place memory in Drosophila. Proc Natl Acad Sci 105: 5579-5584.

Skolnick AI, Davidson RI. 2002. Affective modulation of eyeblink startle with reward and threat. Psychophysiology 39: 835-850.

Smith MP, Buchanan G. 1954. Acquisition of secondary reward by cues associated with shock reduction. J Exp Psychol 48: 123-126.

Solomon RL. 1980. The opponent-process theory of acquired motivation: the costs of pleasure and the benefits of pain. Am Psychol 35: 691-712.

Solomon RL, Corbit JD. 1974. An opponent-process theory of motivation. I. Temporal dynamics of affect. Psychol Rev 81: 119-145.

Steidl S, Li L, Yeomans JS. 2001. Conditioned brain-stimulation reward attenuates the acoustic startle reflex in rats. Behav Neurosci 115: $710-717$

Strack F, Deutsch R. 2004. Reflective and impulsive determinants of social behavior. Pers Soc Psychol Rev 8: 220-247.

Strauss H. 1929. Das Zusammenschrecken. J Psychol u Neurol 39: 111-231.

Sullivan DT, Sullivan MC. 1975. Transport defects as the physiological basis for eye color mutants of Drosophila melanogaster. Biochem Genet 13: 603-613.

Sullivan DT, Bell LA, Paton DR, Sullivan MC. 1979. Purine transport by malpighian tubules of pteridine-deficient eye color mutants of Drosophila melanogaster. Biochem Genet 17: 565-573.

Sullivan DT, Bell LA, Paton DR, Sullivan MC. 1980. Genetic and functional analysis of tryptophan transport in Malpighian tubules of Drosophila. Biochem Genet 18: 1109-1130.

Tanimoto H, Heisenberg M, Gerber B. 2004. Experimental psychology: event timing turns punishment to reward. Nature 430: 983.

Tempel BL, Bonini N, Dawson DR, Quinn WG. 1983. Reward learning in normal and mutant Drosophila. Proc Natl Acad Sci 80: 1482-1486.

Thum AS, Jenett A, Ito K, Heisenberg M, Tanimoto H. 2007. Multiple memory traces for olfactory reward learning in Drosophila. J Neurosci 27: $11132-11138$. 
Tomchik SM, Davis RL. 2009. Dynamics of learning-related cAMP signaling and stimulus integration in the Drosophila olfactory pathway. Neuron 64: $510-521$.

Trannoy S, Redt-Clouet C, Dura JM, Preat T. 2011. Parallel processing of appetitive short- and long-term memories in Drosophila. Curr Biol 21: $1647-1653$.

Tsuchida A, Doll BB, Fellows LK. 2010. Beyond reversal: a critical role for human orbitofrontal cortex in flexible learning from probabilistic feedback. J Neurosci 30: 16868-16875.

Tully T, Quinn WG. 1985. Classical conditioning and retention in normal and mutant Drosophila melanogaster. J Comp Physiol A 157: 263-277.

Tully T, Preat T, Boynton SC, Del Vecchio M. 1994. Genetic dissection of consolidated memory in Drosophila. Cell 79: 35-47.

Turner GC, Bazhenov M, Laurent G. 2008. Olfactory representations by Drosophila mushroom body neurons. J Neurophysiol 99: 734-746.

van Well S, Visser RM, Scholte HS, Kindt M. 2012. Neural substrates of individual differences in human fear learning: evidence from concurrent fMRI, fear-potentiated startle, and US-expectancy data. Cogn Affect Behav Neurosci 12: 499-512.

Wagner AR. 1981. A model of automatic memory processing in animal behavior. In Information processing in animals: memory mechanisms (ed. Spear NE, Miller RR), pp. 5-47. Erlbaum, Hillsdale, NJ.

Wagner AR, Larew MB. 1985. Opponent processes and pavlovian inhibition. In Information processing in animals: conditioned inhibition (ed. Spear NE, Miller RR), pp. 233-265. Erlbaum, Hillsdale, NJ.

Walasek G, Wesierska M, Zielinski K. 1995. Conditioning of fear and conditioning of safety in rats. Acta Neurobiol Exp (Wars) 55: 121-132.

Weike AI, Hamm AO, Schupp HT, Runge U, Schroeder HW, Kessler C. 2005. Fear conditioning following unilateral temporal lobectomy: dissociation of conditioned startle potentiation and autonomic learning. J Neurosci 25: 11117-11124.

Winkler M, Weyers P, Mucha RF, Stippekohl B, Stark R, Pauli P. 2011. Conditioned cues for smoking elicit preparatory responses in healthy smokers. Psychopharmacology 4: 781-789.

Wöhr M, Schwarting RK. 2013. Affective communication in rodents: ultrasonic vocalizations as a tool for research on emotion and motivation. Cell Tissue Res: 354: 81-97.
Wolpe J, Lazarus A. 1966. Behavior therapy techniques. Pergamon Press, New York.

Wolter J, Lachnit H. 1993. Are anticipatory first and second interval skin conductance responses indicators of predicted aversiveness? Integr Physiol Behav Sci 28: 163-166.

Woodworth RS, Schlossberg H. 1956. Experimental psychology. Henry Holt and Company, New York.

Yarali A, Gerber B. 2010. A neurogenetic dissociation between punishment-, reward-, and relief-learning in Drosophila. Front Behav Neurosci 4: 189.

Yarali A, Niewalda T, Chen Y-C, Tanimoto H, Duerrnagel S, Gerber B. 2008. 'Pain relief' learning in fruit flies. Anim Behav 76: $1173-1185$.

Yarali A, Ehser S, Hapil FZ, Huang J, Gerber B. 2009a. Odour intensity learning in fruit flies. Proc Biol Sci 276: 3413-3420.

Yarali A, Krischke M, Michels B, Saumweber T, Mueller MJ, Gerber B. 2009b. Genetic distortion of the balance between punishment and relief-learning in Drosophila. J Neurogenet 23: $235-247$.

Yarali A, Nehrkorn J, Tanimoto H, Herz AV. 2012. Event timing in associative learning: from biochemical reaction dynamics to behavioural observations. PLoS One 7: e32885.

Yovell Y, Abrams TW. 1992. Temporal asymmetry in activation of Aplysia adenylyl cyclase by calcium and transmitter may explain temporal requirements of conditioning. Proc Natl Acad Sci 89: $6526-6530$

Zalocusky K, Deisseroth K. 2013. Optogenetics in the behaving rat: integration of diverse new technologies in a vital animal model. Optogenetics 2013: 1-17.

Zanna MP, Kiesler CA, Pilkonis PA. 1970. Positive and negative attitudinal affect established by classical conditioning. J Pers Soc Psychol 14: $321-328$.

Zars T, Fischer M, Schulz R, Heisenberg M. 2000. Localization of a short-term memory in Drosophila. Science 288: 672-675.

Received September 9, 2013; accepted in revised form January 6, 2014. 


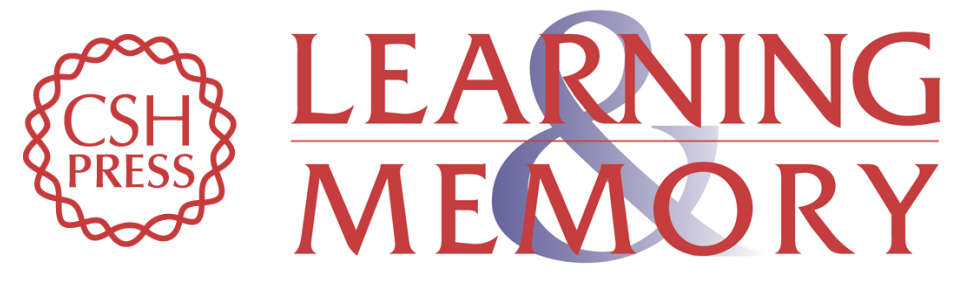

\section{Pain-relief learning in flies, rats, and man: basic research and applied perspectives}

Bertram Gerber, Ayse Yarali, Sören Diegelmann, et al.

Learn. Mem. 2014, 21:

Access the most recent version at doi:10.1101/Im.032995.113

References This article cites 237 articles, 47 of which can be accessed free at: http://learnmem.cshlp.org/content/21/4/232.full.html\#ref-list-1

Creative This article, published in Learning \& Memory, is available under a Creative Commons Commons License (Attribution-NonCommercial 4.0 International), as described at

License http://creativecommons.org/licenses/by-nc/4.0/.

Email Alerting Receive free email alerts when new articles cite this article - sign up in the box at the Service top right corner of the article or click here. 